NIST

PUBLICATIONS
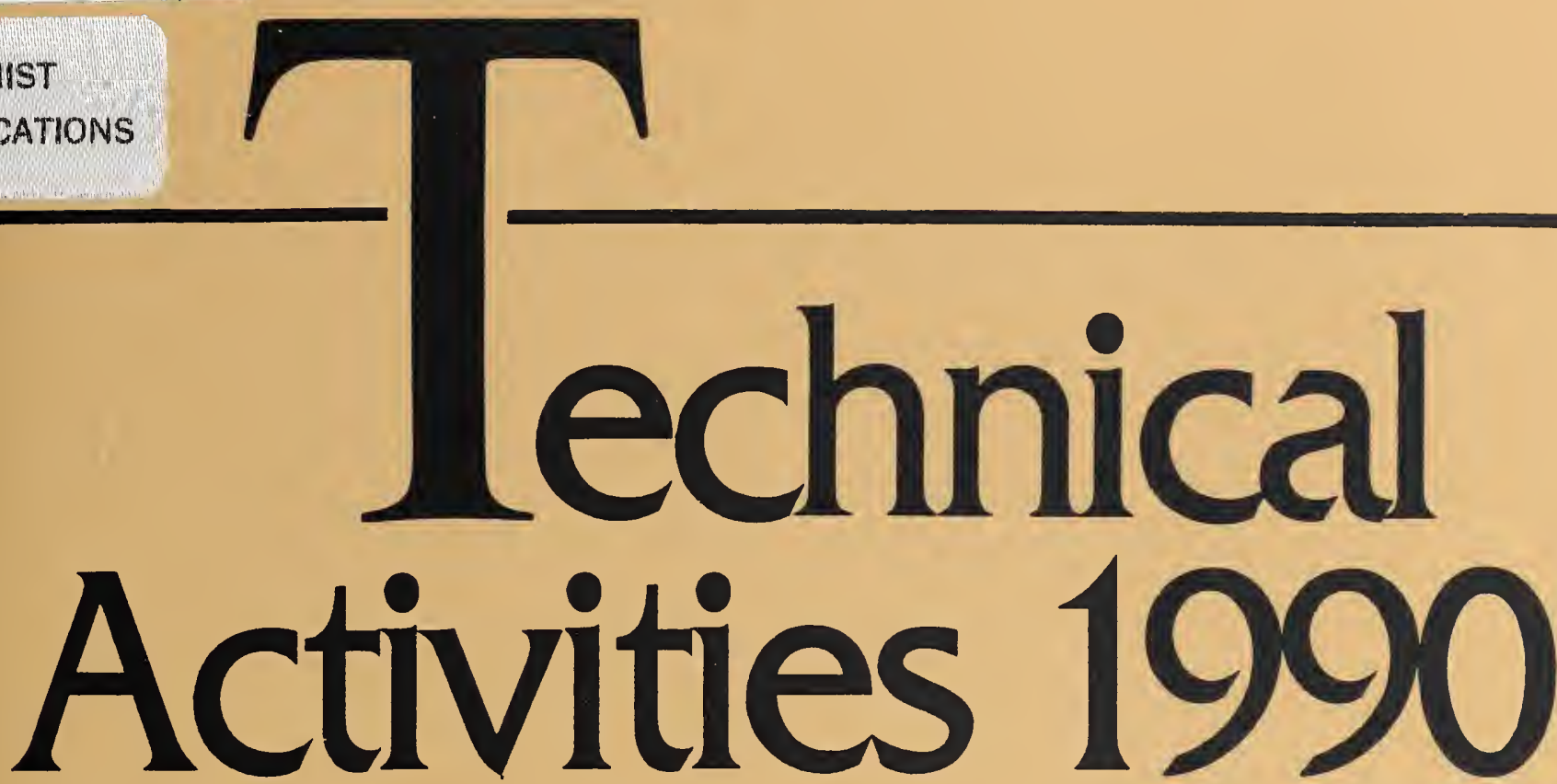

\title{
Standard
}

Reference

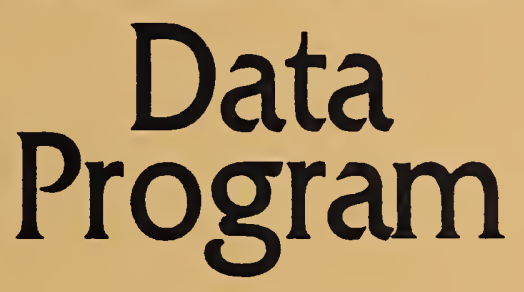

January 1991

U.S. DEPARTMENT OF COMMERCE

QC lational institute of Standards and Technoiogy

100

.056

\#4505

1991

C. 2 


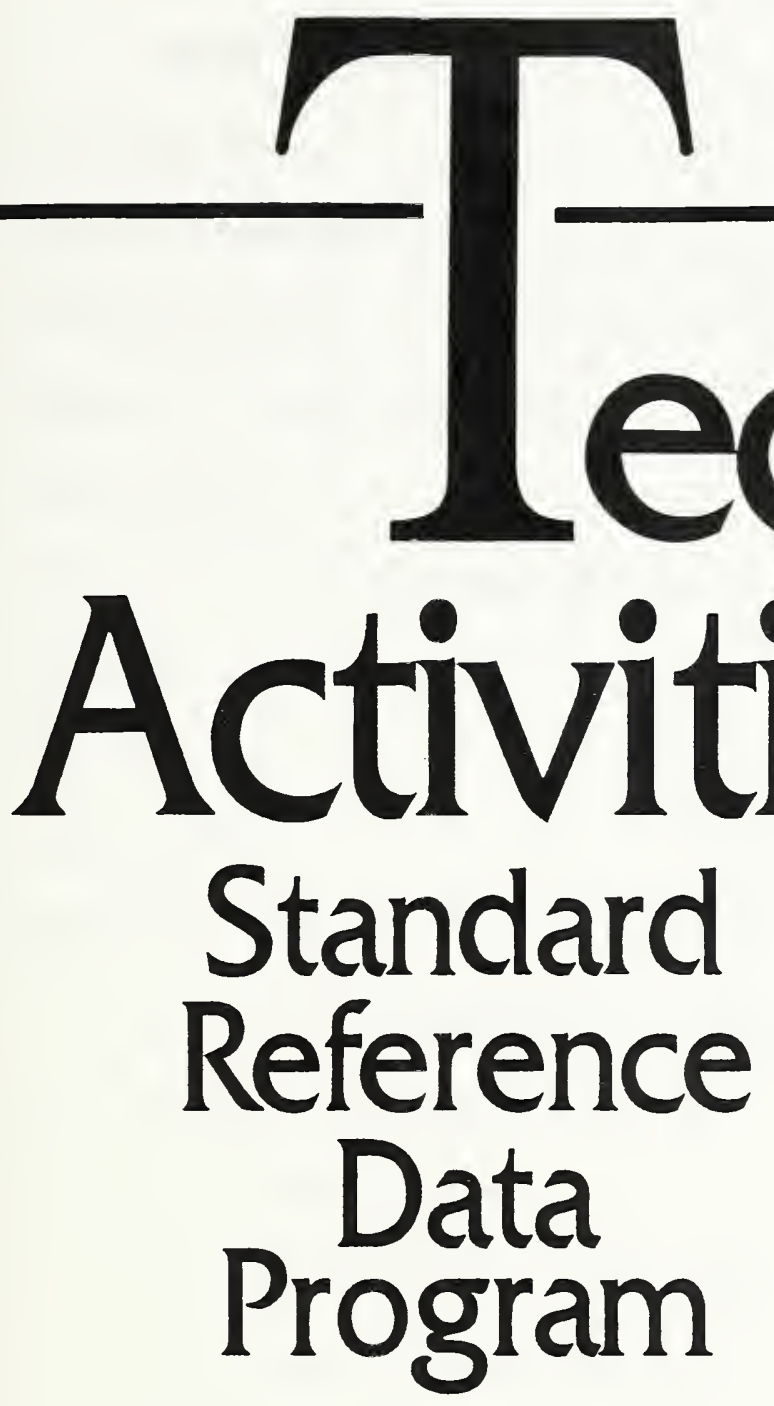

Malcolm W. Chase, Chief

U.S. DEPARTMENT OF COMMERCE

National Institute of Standards and Technology Technology Services

Standard Reference Data Program

Gaithersburg, MD 20899

January 1991

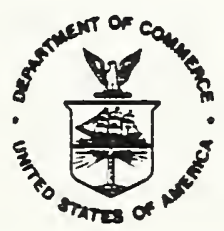



TABLE OF CONTENTS

Introduction.

Program Structure . . . . . . . . . . . . . . . . . . . . . 3

Chemistry Data. . . . . . . . . . . . . . . . . . . . . . . 4

Materials Properties Data . . . . . . . . . . . . . . . . . . 8

Physics Data. . . . . . . . . . . . . . . . . . . . . . . 13

Data Systems Development Group. . . . . . . . . . . . . . . . . . 16

Distribution Center . . . . . . . . . . . . . . . . . . . . 19

SRD Data Centers . . . . . . . . . . . . . . . . . . . . . . . 29

SRD Projects . . . . . . . . . . . . . . . . . . . . . . . . 45

Appendices

A. List of Acronyms and Abbreviations. . . . . . . . . . . . 56

B. SRD Organization Chart . . . . . . . . . . . . . . 58

C. Staff of SRD. . . . . . . . . . . . . . . . . . 59

D. Publications by SRD Staff . . . . . . . . . . . . . 62

E. Talks and Presentations by SRD Staff. . . . . . . . . . . . 63

F. Exhibits by SRD . . . . . . . . . . . . . . . . 65

G. Technical/Professional Committee Participation . . . . . . . 66

H. Standard Reference Data Act (PL90-396) . . . . . . . . . . . 69

I. Functional Statement . . . . . . . . . . . . . . 71

J. NSRDS Data Centers .. . . . . . . . . . . . . . . 72

K. NIST Organization Chart . . . . . . . . . . . . . 76

L. Technology Services Organization Chart. . . . . . . . . . . . . 77 
Standard Reference Data is a program office within the office of Measurement Services in Technology Services, National Institute of Standards and Technology. Standard Reference Data develops and disseminates publications and databases of critically evaluated physical, chemical, and materials properties of substances. These publications and databases are available through NIST and private publishers, on magnetic tape and PC diskettes, and from online retrieval systems.

Standard Reference Data is responsible for management and coordination of the program. Work is carried out through a decentralized network of data centers and projects referred to as the National Standard Reference Data System (NSRDS). This volume summarizes the activities of the program for the fiscal year 1990.

Key words: Chemistry data; data compilation; evaluated data; materials properties data; numerical database; physics data; standard reference data; technical activities 1990 . 

Standard Reference Data is responsible for program management and coordination of the National Standard Reference Data System (NSRDS). The major aim of the program is to provide critically evaluated numerical data to the scientific and technical community in a convenient and accessible forr: Other outputs, such as annotated bibliographies, data collections, and procecises for computerized handling of data are also made available. A second ain is to provide feedback into experimental and theoretical programs to help raise the general standards of measurement and provide guidance as to the relative needs of various data. By communicating the experience gained in evaluating the world output of data in the physical sciences, NSRDS helps to advance the level of techniques applied to research and development and improve the reliability of physical measurements. A third aim is to contribute to the U.S. competitive edge through providing technological efforts with the most recent and reliable reference data on which to base design of processes and applications.

The formal existence of the NSRDS dates from 1963, when the Federal Council for Science and Technology asked the National Bureau of Standards (since renamed the National Institute of Standards and Technology [NIST]) to assume primary responsibility in the Federal Government for promoting and coordinating the critical evaluation of numerical data in the physical sciences. The program was conceived as a decentralized national effort, with financial support coming from a variety of Government and private sources, but with NIST responsible for the overall planning and coordination. In 1968 the Congress provided a specific legislative mandate for the program through passage of Public Law 90-396, the Standard Reference Data Act. (See Appendix G.) This Act states the policy of the Congress to make reliable reference data available to scientists, engineers, and the general public, and it encourages cooperation among NIST, other Federal Agencies, and the private sector in meeting this objective.

The technical scope of the program gives primary emphasis to well-defined physical and chemical properties of substances and systems which are well characterized. Also included are engineering materials (alloys, ceramics, etc.) whose composition may vary only within clearly stated ranges. While these definitions leave many borderline cases, the overall intent is to concentrate the effort on intrinsic properties that are clearly defined in terms of accepted physical theory and substances whose composition and history are so well known as to justify evaluation of the data. Biological properties and data relating to large natural systems (e.g., the atmosphere, the oceans) also fall outside the program.

Standard Reference Data monitors and coordinates the work of the various data centers and specialized projects which collectively make up NSRDS. These projects are located in the technical divisions of NIST and in universities, industrial laboratories, and other Government laboratories. Close association between data evaluation projects and relevant experimental research programs enhances the critical judgment essential to assure the reliability of the final output. 
The principal output of the program consists of compilations of evaluated data and critical reviews of the status of data in particular technical areas.

Evaluation of data implies a careful examination, by an experienced specialist, of all published measurements of the quantity in question, leading to the selection of a recommended value and statement concerning its accuracy or reliability. The techniques of evaluation depend upon the data in question, but generally include an examination of the method of measurement and the characterization of the materials, a comparison with relevant data on other properties and materials, and a check for consistency with theoretical relationships. Adequate documentation is provided to enable a nonexpert to understand the selection of recommended values and accuracy estimates.

Evaluated data produced under the NSRDS program are disseminated through the following mechanisms:

National Standard Reference Database Series - computer-readable databases available in magnetic tape and diskettes.

Journal of Physical and Chemical Reference Data - A bimonthly journal containing data compilations and critical data reviews, published for the National Institute of Standards and Technology by the American Institute of Physics and the American Chemical Society. [This journal was published on a quarterly basis through 1989.]

NIST publication series (such as Technical Notes, Special Publications, etc.) distributed by the Superintendent of Documents, U.S. Government Printing office.

Publications of technical societies and commercial publishers.

Written and verbal responses by SRD and individual data centers and data projects to inquiries for specific data. 
Current numeric activities in NIST Standard Reference Data are carried out in 22 data centers and approximately 32 short-term projects located in the technical divisions of NIST and in academic and industrial laboratories. Each of these activities undertakes the collection and evaluation of the available data on a specified set of properties and substances. The activities are aggregated into three discipline-oriented program areas:

Chemistry Data - Covers primarily kinetic, thermodynamic, and transport properties of substances important to the chemical and related industries.

Materials Properties Data - Includes structural, electrical, optical, and mechanical properties of solid materials of broad interest.

Physics Data - Includes data on atomic, molecular, and nuclear properties, and spectral data utilized for chemical identification.

Since comprehensive coverage of all properties and materials of importance in these three program areas is not feasible, Standard Reference Data (SRD) selects data sets of highest priority, based upon the present and anticipated applica. tions of the data. The current focus in each area is described in the following sections.

In addition to its planning and coordinating role, SRD is responsible for dissemination of the results from the projects it supports. The evaluated data are made available in both printed and computer-readable form. Response to specific inquiries directed to SRD and/or the individual data centers forms another dissemination mode. There are two additional groups in SRD responsible for aiding the dissemination process.

Data Systems Development Group - Supports the data centers' work with computer equipment and software and gives programming assistance; processes evaluated data from magnetic media, writes and evaluates databases and typesetting publications to be distributed by SRD.

Distribution Center - Delivers to the technical community the results of scientific efforts conducted under the SRD Program, including data compilations in both printed and electronic form.

The current thrust of each group is also described in the following sections. 
The Chemical Data Program deals primarily with data describing the properties of individual substances and mixtures and data describing the properties of chemical reactions between substances. The properties include: physical properties (such as density), equilibrium and thermodynamic properties (such as equilibrium constants and heat capacities), transport properties (such as viscosity and thermal conductivity), and time-dependent properties (such as rate constants). Thermodynamic and time-dependent properties have applications to chemical reactions as well as individual substances and mixtures.

\section{Structure of the Program}

The program consists of a number of data centers and data projects. Data centers are continuing in nature. Their staffs take responsibility for coverage of the data in their fields of specialization and produce an ongoing series of products which provide critically evaluated reference data in the field in question. Data Projects are similar in character. However, they are of shorter term and are directed at one or a few specific products. The large data centers often receive support from more sources than the Standard Reference Data Program. Data centers' activities will in general cover more subjects than those directly supported. In fact, one center, The National Center for the Thermodynamic Data of Minerals (U.S. Geological Survey), receives no direct support from SRD, but is recognized as an important participant in the National Standard Reference Data System.

\section{Table 1}

Data Centers in the NSRDS Program for Chemical Data

Aqueous Electrolyte Data Center, NIST Gaithersburg

Chemical Kinetics Data Center, NIST Gaithersburg

Chemical Thermodynamics Data Center, NIST Gaithersburg

Fluid Mixtures Data Center, NIST Boulder

Ion Kinetics and Energetics Data Center, NIST Gaithersburg

Molten Salts Data Center, Rensselaer Polytechnic Inst.

National Center for the Thermodynamic Data of Minerals

U.S. Geological Survey

Thermodynamic Research Center, The Texas A\&M University 


\section{Table 2}

\section{Data Projects in the NSRDS Program for Chemical Data}

Thermophysical Properties Data for Fluids, University of Maryland Equations of State for Mixtures of Argon, Nitrogen, Oxygen and of Air, University of Idaho

International Center for the Systematic Correlation and Dissemination of

the Transport Properties of Fluids, Brown University

Properties of Polar Fluids, NIST Gaithersburg

Design Institute for Physical Properties Data, AIChE

Properties of Helium, University of Oregon

Application of Expert Systems to Critical Evaluation of Thermophysical

Property Data, Texas A\&M Research Foundation

Data on Aqueous Electrolytes, University of Delaware

Gibbs Energies of Formation for Kreb's Cycle and Related Compounds, University of California, San Diego

A Centralized Database for Thermodynamic Data on Lipid Mesomorphic Phase

Transitions and Miscibility, Ohio State University

Properties of Transition Metal Coordination Complexes, Boston University

$\mathrm{OH}$ Radical Reactions with Organic Compounds, University of California, Riverside

\section{Cooperative Activities}

Cooperative activities play a major role in the program for several reasons. There is little value in competitive evaluation programs since a primary purpose for developing evaluated reference databases is to provide users with a common source of data to enhance comparability and consistency in calculations involved in a wide variety of uses, an example being custody transfer between supplier and purchaser of carbon dioxide. Multiple sources of reference data for the same property create confusion and unproductive work. Furthermore, funding and skilled personnel for reference-data activities are severely limited throughout the world.

The cooperative activities can be divided loosely into national and international parts. The primary national activities involve the AIChE Design Institute for Physical Property Data (DIPPR) which is a cooperative organization of chemical companies (primarily, but not exclusively, U.S. companies). DIPPR carries out data evaluation and experimental measurements to provide reference data for the chemical industry. SRD and DIPPR cooperate in a number of ways. SRD is one of many sponsors of DIPPR. SRD carries out selected projects for DIPPR and acts as distributor for automated products for DIPPR. SRD also cooperates in a less formal way with the data programs of the American Petroleum Institute and the Gas Processors Association, and ASME through its Research Committee on the Properties of Steam.

Major international cooperative activities are carried out through CODATA, the International Union of Pure and Applied Chemistry (IUPAC), and the International Association for the Properties of Water and Steam (IAPWS). 
The CODATA Task Group on Chemical Thermodynamic Tables is an international organization involved in preparing a thermodynamically consistent set of tables for formation properties at the standard conditions and thermal functions for a wide range of inorganic substances and their solutions in water. Preparation of these tables involves scientists in four countries on a regular basis and others, depending on their interest in the substances involved. Two books from this task group have been published, and a third major effort is underway. The Task Group also cooperates with another CODATA Task Group on Geochemical Thermodynamic Data and a committee of the Organization for Economic Co-operation and Development (OECD).

Cooperation with IUPAC is centered in the Subcommittee on Thermodynamic Tables and the Subcommittee on Transport Properties of the Commission on Thermodynamics. For many years the Subcommittee on Thermodynamic Tables has sponsored the Thermodynamic Tables Project at Imperial College. The project has published the series, International Thermodynamic Tables of the Fluid State, several of which have involved formulations developed in the SRD program. The subcommittee has also produced other products which do not involve the tables project at Imperial College. The Subcommittee on Transport Properties prepares standards and evaluated data on the transport properties of fluids.

The cooperation with IAPWS is of many kinds. IAPWS is involved with the production of reference data on the properties of water itself, as a working fluid, and on the properties of aqueous solutions which are involved in the power cycle used in generating electricity and can participate in a variety of corrosion and deleterious interactions with the materials of the machinery. Some of the formulations for water endorsed by IAPWS have been produced through SRD, and the work on solutions is closely related to that of the Aqueous Electrolyte Data Center and the Properties of Polar Fluids group.

\section{Computerization and Automation}

A major, and increasing, factor in the activities of the Standard Reference Data Program is automation. Several types are involved. Individual data centers usually have large holdings of bibliographic references, abstracts of relevant articles, and lists of unevaluated experimental data, as presented by the original author or converted to a common set of units, temperature scale, reference base, etc. These are most efficiently kept and handled in computerized files. They also have substantial needs for software programs, a common example being a non-linear regression package which can be used to determine the value of an expression which results from fitting to data for several properties simultaneously.

Automation is increasingly involved in producing final outputs. Cameraready tables may be produced in magnetic form to avoid typesetting and subsequent detailed proofreading. Finally, there is an increasing demand for automated databases for a wide variety of uses. These characteristically involve numerical data and references, or generating equations for them, and software to aid the user in retrieving the data wanted. 


\section{Outputs}

Exanination of SRD Database Sales on page 21, and the publications which appeared in J. Phys. \& Chem. Ref. Data for 1990 on pages 22-25, identify the principal outputs for the SRD chemistry data program. 
Several major milestones were accomplished in 1990 in the Materials Properties Data Program.

- Publication of Volume 8 of Phase Diagrams for Ceramists

- Release of the NIST Structural Ceramics Database

- Release of ACTIS Tribomaterials I Database

- Release of new expert systems on corrosion performance of materials

- Publication of new monographs on Alloy Phase Diagrams

- Publication of Comprehensive Bibliography on Phase Diagrams for Ceramists

- Release of CD-ROM versions of NIST Crystal Data and NIST/Sandia/ICDD Electron Diffraction Database

Each of these events represents the culmination of several years of work by the data centers and Data Projects that make up the SRD Materials Properties Data Program. The program has five major thrusts as shown in Table 1.

\title{
Table 1
}

\section{SRD Materials Properties Data Program}

\author{
Structure and Characterization \\ Physical Properties \\ Phase Equilibria \\ Performance Properties \\ Corrosion \\ Mechanical Properties \\ Tribology \\ Computer Access and Databases
}

The work is accomplished in a variety of ways. Five ongoing data centers and activities exist: Crystal Data, Structural Ceramics, Phase Diagrams for Ceramists, Corrosion, and Tribology. In addition, the NIST/ASM Alloy Phase Diagram Program continues. Each has cooperative agreements linking its activities to major outside technical groups (Table 2). This ensures that the data center work addresses the needs of the U.S. research and technical communities. Work is often jointly funded and, in some cases, substantial amounts of industrial support have been raised for these programs. 
Table 2

Major NIST-Outside Data Agreements

\section{Society}

ASM International

American Ceramic Society

International Centre for Diffraction

Data-JCPDS

National Association of Corrosion

Engineers

ACTIS, Inc.

Gas Research Institute
Data Area

Alloy Phase Diagrams

Phase Diagrams for Ceramists

Crystal Data

Corrosion

Tribology

Structural Ceramics

The Materials Properties Data Program also has a number of short-term evaluation projects that address specific data needs within the framework given in Table 3. These projects are done both inside and outside NIST. A major part of the program is to develop the tools and technology for computerizing materials properties data. This requires cooperative efforts with American and international standards organizations. In 1990, great progress has been made.

\section{Structure and Characterization}

The structure and characterization of solid materials is a fundamental concern. The identification of unknown substances has always been a major use of evaluated data. The NIST Crystal and Electron Diffraction Data Center has two important tools related to crystalline materials. The NIST Crystal Data File, updated again in 1990, now has data on over 140,000 compounds. The database comes with software to analyze experimental measurements and then search the database for matching entries. Negotiations have been completed to integrate this database directly into diffractometers.

One outgrowth from the NIST Crystal Data File is the NIST/Sandia/ICDD Electron Diffraction Database, released in 1987. Important parameters have been calculated from the NIST Crystal Data File and combined with other data from the ICDD's Powder Diffraction File to make the new Electron Diffraction Database which is being incorporated directly into electron diffraction instruments. 
Table 3

Active SRD Materials Properties Data Program - 1990

Structure and Characterization

Crystallography

NIST Crystal Data Center

Surfaces

Cambridge Crystallographic Data Centre

X-ray Photoelectron Spectroscopy Database - NIST

Ion Sputtering - NIST

Surface Extended X-ray Absorption Fine Structure - Oregon

State University

Molecular Adsorption on Transition Metals - Rutgers University

Physical Properties

Properties of Glassy-Forming Melts - Alfred University

Polymer-Polymer Miscibility Data - Rensselaer Polytechnic

Phase Equilibria

Institute

Alloys

NIST Alloy Phase Diagram Program

$\mathrm{Fe}$ - ASM International

Editor of Bulletin of Alloy Phase Diagrams - J. F. Smith, Iowa State

Ceramics

NIST Phase Diagrams for Ceramists Data Center

Corrosion

NIST Corrosion Data Center

NIST/NACE Corrosion Data Program

Crevice Corrosion of Stainless Steels - LaQue Center - North

Carolina

Mechanical Properties

Fatigue Crack Propagation of Metals - University of Tulsa

Structural Ceramics Data Center - NIST

Tribology

Tribology Information Activity - NIST

The characterization of surfaces is the other major component of this part of the program. The NIST X-ray Photoelectron Spectroscopy Database has been released to the public, and more than 150 copies have been distributed. Data on over 13,000 compounds are included, and the PC database features an easy-touse interface.

Two SRD data evaluation projects on surface data are nearing completion. The project on surface coverage of adsorbed molecules has had a manuscript submitted to the Journal of Physical and Chemical Reference Data. Work of comparing surface structure data generated by surface extended $x$-ray absorption fine structure techniques (SEXAFS) with low-energy electron diffraction data is also near completion. 


\section{Physical Properties}

Very little effort is going on in this area at present. Discussions on data evaluation work for new high $T_{c}$ superconductors have been held, but no projects have been formulated.

Results from data evaluation work done at RPI under the direction of Professor Krause for polymer-polymer miscibility will be published next year.

A project on properties of glassy-forming melts is about done. This project is being done in conjunction with the International Commission on Glass and represents the first major data evaluation effort in the area.

\section{Phase Equilibria}

NIST, through the Materials Science and Engineering Laboratory (MSEL) and SRD, has two major programs for evaluating phase data for alloys and ceramics. These programs are integrated into the user communities, and considerable progress was achieved last year.

The Phase Diagrams for Ceramists Data Center has completed preparation of Volume 8 of its series Phase Diagrams for Ceramists as part of the joint program with the American Ceramic Society. About 215 critical evaluations and over 900 individual phase diagrams are included.

A PC database and graphics program for ceramics phase diagrams had been completed in 1988. Testing by users has led to improvements, and the database should be completed in 1990 .

The ASM/NIST Alloy Phase Diagram Program has continued and ASM International has issued the Second Edition of the compendium Binary Alloy Phase Diagrams. Professor Jack Smith of Iowa State, under contract, still is editor for the Bulletin of Alloy Phase Diagrams.

\section{Performance Properties}

\section{Corrosion}

The NACE-NIST Corrosion Data Program has added new products to their already successful databases, based on the NACE Corrosion Data Surveys. A corrosion data management system has been released and contains the provision for adding proprietary data.

In addition, the NACE-NIST has developed a second expert system module for materials selection for process and storage equipment in the chemical industry. This project, sponsored by the Materials Technology Institute (MTI), added an expert system for materials in contact with acetic acid that was distributed to MTI's members for their use in 1990. Six additional modules are under development. 


\section{Mechanical Properties}

The SRD effort on mechanical properties data focuses on developing techniques and methods for evaluating these data. Since mechanical properties generally result from standardized tests, the assessment of the data quality is different from data on the intrinsic properties of materials.

This year the NIST Structural Ceramics Database was released, the first publicly available database on ceramics. The focus was on silicon carbides and silicon nitrides and all data were evaluated by the NIST Structural Ceramics Data Center. Work is already under way to add other existing computerized files. In addition, the data center is exploring the development of a prototype expert system to aid in greater use of ceramics.

The project on evaluation of fatigue crack propagation data for ferrous and nonferrous metals of importance to the automotive industry continues at the University of Tulsa. One outgrowth has already been a draft ASTM standard for data recording formats for these data.

\section{Tribology}

A multi-agency program for tribology data, started in 1986, is now well under way. NIST is working together with ACTIS, Inc. and others to improve the quality of tribology data, build databases, and develop expert systems.

During 1990, the first product of this effort, Tribomaterials I Database, was marketed by ACTIS, Inc. This database contains data on over 270 materials commonly used in tribological situations, both unlubricated and lubricated wear.

\section{Computer Access and Databases}

The strong SRD effort to help bring about computerization of materials data has continued, and major accomplishments were achieved in 1990. Several database efforts have already been discussed. Other areas deserve mention.

SRD has been in the forefront of developing standards for materials databases to promote uniformity and compatibility between different materials databases. Standards are needed for identification of materials and reporting of test results. SRD has vigorously participated in both ASTM Committee E-49 on Computerized Materials Data, the ISO TC184/SC4/WG3 Standard for Exchange of Product Data (STEP) and the VAMAS Technical Working Group 10 on Factual Materials Databanks.

During 1990, ASTM Committee E-49 passed four standards on the Society level and more are being written. Committee E-49 under SRD leadership also expanded its scope to include chemical databases. Finally, the STEP Materials Model has been completed and now is undergoing international review. 
The Physics Data Program involves data centers and projects concerning properties associated with the disciplines of physics and physical chemistry. These include fundamental physical constants, atomic and molecular spectroscopy, collisions of low- and medium-energy electrons with gas phase media, the interaction of high-energy photons and charged particles with matter, reactions of radicals and transient species in solution, and energy levels of transient species. One data center in analytical chemistry, the NIST Mass Spectrometry Data Center, is also included in the Physics Data program.

\section{Structure of the Program}

The annual activities of the individual data centers are described in the section entitled Data Center Reports. Each Center continues an established "pattern" for a selected body of data definea $\mathbb{E}$ clearly stated criteria. A comprehensive bibliography is developed, a library of articles acquired, data are extracted and evaluated, recommended data are entered in a computer file, and an output mode is designed. The output file is designed to print hard-copy tables and/or as a computerized database accessible via a database management system. The output is distributed to the public, and the cycle begins again. A new data body is selected for review. Details of this process vary among the different data centers, but the ongoing pattern is generic. Lists of the data centers and projects are given in Tables 1 and 2, respectively.

\section{Table 1}

Data Centers in the NSRDS Program for Physics Data

Atomic Energy Levels, NIST Gaithersburg

Atomic Transition Probabilities, NIST Gaithersburg

Atomic Collision Cross Sections, JILA Boulder

NIST Mass Spectrometry, NIST Gaithersburg

Molecular Spectra, NIST Gaithersburg

Photon and Charged Particle, NIST Gaithersburg

Radiation Chemistry Data Center, Notre Dame University

Fundamental Constants, NIST Gaithersburg

\section{Table 2}

Data Projects in Physics Program

Energy Levels of Transient Molecules, NIST Gaithersburg Electron Collisional Data for Plasma Processing and Modeling (Univ. of Colorado) NSF funding

An Evaluated Compilation of Ion Solvation Energetics (Univ. of Tennessee) NSF funding

Resonance Ionization Spectroscopy (Univ. of Tennessee) NSF funding 
Noteworthy outputs from the Physics Data Program for FY 1990 include:

Version 3.0 of the "NIST/EPA/MSDC Mass Spectral Database" containing approximately 5000 new spectra was released in both PC and magnetic tape versions. The "Mass Spectral Database of Common Compounds" which contains spectra for only 10,215 compounds was also released at about a third the price of the full database. This version is attractive to many users because, although it contains spectra for most commercialy available compounds as well as those of environmental or pharmaceutical interest, it requires only a fraction of the disk space needed for the full database.

"NIST Transition Probabilities for Scandium Through Nickel" were made available on PC diskette as NIST Standard Reference Database 24.

"NIST Vibrational and Electronic Energy levels of Small Polyatomic Transient Molecules" was completed. This program provides rapid access to experimental data for approximately 1000 molecules giving vibrational fundamentals of ground-state and excited-state transient molecules and electronic energy levels of these species. The companion article "Vibrational and Electronic Energy Levels of Small Polyatomic Molecules. Supplement I." was published in the Journal of Physical and Chemical Reference Data (19, 1387 (1990)).

Energy level compilations on 24 copper spectra (Cu VI - Cu XXIX) and 16 sulphur spectra (S I - S XVI) were published [J. Sugar and A. Musgrove, J. Phys. Chem. Ref. Data 19, 527 (1990) and W. C. Martin, R. Zalubas, and A. Musgrove, J. Phys. Chem. Ref. Data 19, 821 (1990), respectively]. Spectral data and Grotrian Diagrams for highly ionized iron (Fe VII - Fe XXVI) were published (J. Phys. Chem. Ref. Data 19, 127 (1990). Wavelength and energy level classifications for 12 magnesium spectra (Mg I - Mg XII) were accepted for publication [V. Kaufman and W. C. Martin, J. Phys. Chem. Ref. Data 20 (1990)].

Development of an Atomic Spectroscopy Database containing wavelengths, energy levels, and transition probabilities for all atoms and atomic ions continues. Capability of entering data directly into the database and retrieving on a variety of characteristics has been completed. Publications were prepared directly from the database.

- Critical reviews of kinetic data for reactions of peroxyl radicals in fluid solution and of one-electron reduction potentials for couples involving radicals in aqueous solution were published [P. Neta, $R$. E. Huie, and A. B. Ross, J. Phys. Chem. Ref. Data 19, 413 (1990)].

In the area of photon energy absorption, two publications were completed: "Annotated and Indexed Bibliography of Experimental Photon-Attenuation Coefficients for Compounds," NISTIR 90-4282, J. $\mathrm{H}$. Hubbell and "Bibliography and Current Status of K, L, and Higher Shell Fluorescence Yields for Computation of Photon Energy-Absorption Coefficients," NISTIR 89-4144, J. H. Hubbell. 
- "Recommended Values of the Fundamental Physical Constants: A Status Report" (for the CODATA Task Group on Fundamental Constants), Barry N. Taylor and E. Richard Cohen, J. Res. Natl. Inst. Stand. Technol. 95, 497 (1990).

These data products are typical outputs from the ongoing efforts of the SRD Physics Data Program which provides a steady stream of reliable evaluations in both hard copy and computerized format. Resources have limited expansion of activity into new areas where SRD involvement is appropriate such as molecular energy levels and molecular transition probabilities, and resonance ionization mass spectroscopy schema.

Data center staff members have remained active participants in national and international data programs such as the International Atomic Energy Agency, IUPAC, the International Commission on Radiation Units and Measurements, CODATA, the Consultative Committee on Electricity, and the AIP Committee on Numerical Databases.

Dr. John Broad was appointed Director of the Atomic Collision Cross Section Data Center at the Joint Institute of Laboratory Astrophysics. The Department of Energy granted funds to support a major upgrade in computing equipment under the condition that it be matched with NIST resources. The system selected built around a DECstation 5000 workstation is presently being installed. 
The Data Systems Development Group (DSDG) has balanced the review of new and updated databases with database development. In publications, DSDG has increased JPCRD production and expedited processing by modernizing the equipment.

\title{
Publications
}

The DSDG staff involved with publications continues to write programs for conversion of word processor and other magnetic media files to Bedford format for the typesetting of:

\author{
JPCRD \\ Technical Notes \\ Monographs \\ SRD Newsletters \\ Database Users' Guides (distributed with SRD databases)
}

The publications staff has increased the number of JPCRD papers in each issue which are done in-house. This is particularly notable in that JPCRD is now published six rather than four times each year. This saves SRD money and very importantly increases the efficiency and timeliness with which we are able to produce each issue.

From the many scientific papers published by SRD on such topics as atomic physics, thermal properties, transport properties, and many others, SRD plans to produce computerized databases of the same information. This year the Vibrational and Electronic Energy Levels of Small Polyatomic Transient Molecules was made available as both a publication in JPCRD and as a database.

\section{Electronic Products}

Major Database Upgrades Reviewed:

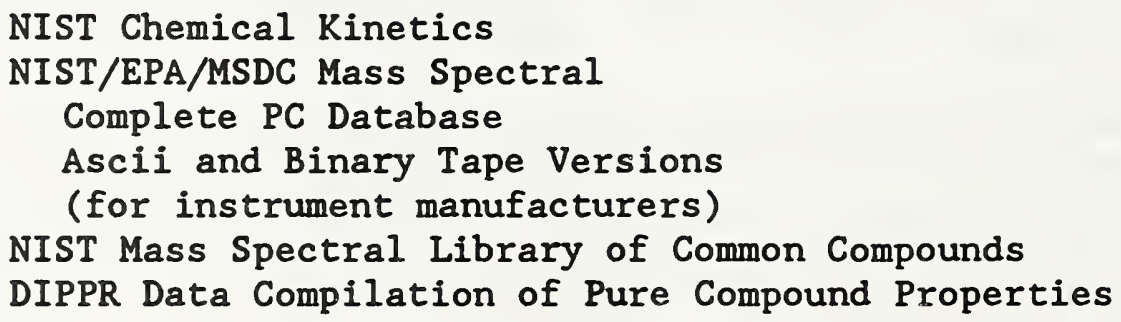

New Databases Reviewed and Released:

NIST Binary Images of Printed Digits, Alphas, and Text Thermophysical Properties of Hydrocarbon Mixtures

PC Database

Object Module Library

Source Code for Subroutines

NIST Thermophysical Properties of Refrigerants and

Refrigerant Mixtures

NIST Positive and Negative Ion Energetics 
NIST Estimation of the Thermodynamic Properties for

Organic Compounds at $298.15 \mathrm{~K}$

NIST Structural Ceramics of Silicon Carbides and

Silicon Nitrides

NIST Atomic Transition Probabilities

NIST X-ray and Gamma-ray Attenuation Coefficients and

Cross Sections

(Menu system implemented by DSDG)

Databases Written by DSDG Staff:

NIST Vibrational and Electronic Energy Levels of Small Polyatomic Transient Molecules

NIST/CARB Biological Macromolecule Crystallization

(First biotechnology product marketed by SRD)

Projects Currently Under Review

NIST Thermodynamic and Transport Properties of Molten

Salts

A Soviet Thermodynamics Database

(a joint project with Hemisphere Press)

NIST Heat Capacities of Organic Compounds

NIST Thermodynamic Properties of Refrigerants and

Refrigerant Mixtures

(upgrade with additional refrigerants and the

capability of mixing up to 5 refrigerants)

NIST/ACERS Phase Diagrams for Ceramists

NIST Structures and Properties

DSDG is writing a major upgrade to the NIST X-ray Photoelectron Spectroscopy Database. A data entry program, for the use of the data evaluators, has just been completed and work is under way to programmatically extract registry numbers from other SRD databases for use in this upgrade.

A revised version of the NIST Lipid Thermotropic Phase Transition Database is now being built. This will be SRD's second product in the biochemical/technology market.

Continued work by DSDG staff in support of data center automation has produced significant new output.

1. An index linking the NIST Crystal Data file to the Joint Committee on Powder Diffraction file has been built. The Index will be used to enhance a CDROM project.

2. The Atomic Physics data have been organized into Oracle databases. Software has been written around Oracle to bulk load these databases, to provide a data entry program for data center personnel, to prepare publications with typesetting included, to provide data center reports and communications for inquiries, and to provide data for a NASA collaborative project. 
The Data Systems Development Group supports and manages: the HP UNIX minicomputer for data processing and maintenance of data systems (i.e., Crystal, NBS Tables of Chemical Thermodynamic Properties, the JANAF Thermochemical Tables, Atomic Energy Levels, Atomic Transition Probabilities); the Bedford UNIX system for publications; the development PC's (286 and 386 computers) and the Macintosh work station for the production and review of marketable PC databases; and the SRD staff's PC's, including those used for database production for distribution. In addition, we are responsible for maintenance and backup procedures for the HP 1000 (RTE-A) minicomputer in the Chemical Thermodynamics Data Center. We continue to utilize the CDC super computer for production of the several versions of the Mass Spec tapes.

The publication section's work will be streamlined by our recent acquisition of a Tegra image controller and 800 dpi printer. All printing and final document preparation can now be made in-house. Larger, faster disk drives were installed on these typesetting systems to accommodate the increased load of publications; they also expedite the use of the software for the new image controller.

The Unix computer operating system was upgraded several steps to version 7.0 which is the most current version. Subsequently, the Oracle database management system and the Graphicus graphics software were upgraded as well. A new piece of software for this computer was obtained from the TRC data center which allows searching of our joint registry number files.

SRD's communications knowledge and file transfer abilities continue to expand. We have local area networks (LAN's) in both the database building section and the publishing section of our operations. The database LAN is connected to the new NIST high-speed backbone. We plan to make the HP UNIX computer a file server for our local network. We will also be connecting the distribution center to the LAN.

SRD continues to test all distributable databases in the PC MKS environment (UNIX) and the Macintosh environment. Microsoft Windows is the next environment in which we will be testing the SRD databases. We have been so successful at having our PC products run on the Macintosh computer in a PC emulation mode that actual conversions to that environment have been set at a lower priority.

SRD sponsored a workshop called Solutions Day where DSDG and Data Center personnel presented various software options for database development. The software products discussed included database management systems, menu systems, graphics packages, and database engines. 
SRD Distribution Center acts as a focal point for technical inquiries on data compilations in printed and electronic form including The Journal of Physical and Chemical Reference Data and The NIST Standard Reference Database Series from scientists in industry, government, and the academic community. As distribution center for the databases, personnel in this office negotiate licenses and process and receive database monies. PC databases, including various updates and documentation, are reproduced here. Distribution personnel actively promote SRD products by designing, writing, and typesetting various promotional items, including the SRD Newsletter The Reference Data Standard, brochures, and database announcements. A major marketing thrust was begun with the publication of NIST Standard Reference Data Products 1990 Catalog, which will be updated yearly, and advertisements which appeared in several national scientific journals.

The following tables summarize the output of the program and the distribution of this output:

\begin{tabular}{cc}
\multicolumn{2}{c}{ Inquiries Received in SRD } \\
(Does not include inquiries from Data Centers) \\
\hline \\
Year & $\frac{\text { Number }}{657}$ \\
1981 & 613 \\
1982 & 1022 \\
1983 & 616 \\
1985 & 623 \\
1986 & 926 \\
1987 & 2172 \\
1988 & 2010 \\
1989 & 2905 \\
1990 & 2910
\end{tabular}

Publications in 1990

Series

JPCRD, vol. 19

Data Compilations

from Other Publishers

Other Publications

in NIST Series

Total
Pages Published

1645

2428

279

4352
Titles Published

31

17

3

51 
Sales of JPCRD Reprints and Supplements

$\begin{array}{ccr}\text { Year } & \text { Reprints } & \text { Supplements } \\ 1981 & 4254 & 137 \\ 1982 & 3567 & 266 \\ 1983 & 3081 & 1666 \\ 1984 & 2900 & 1300 \\ 1985 & 3180 & 547 \\ 1986 & 2019 & 383 \\ 1987 & 1906 & 2222 \\ 1988 & 3926 & 1376 \\ 1989 & 3128 & 2026 \\ 1990 & 2151 & 1046\end{array}$

Subscribers to JPCRD

Month/year Number

$\begin{array}{rr}9 / 1981 & 1265 \\ 9 / 1982 & 1234 \\ 9 / 1983 & 1230 \\ 9 / 1984 & 1186 \\ 9 / 1985 & 1160 \\ 8 / 1986 & 1087 \\ 9 / 1987 & 1076 \\ 9 / 1988 & 1047 \\ 9 / 1989 & 991 \\ 11 / 1990 & 1032\end{array}$


NIST/EPA/MSDC Mass Spectral Database Version 2.0 (PC)

Version Upgrade from 2.0-3.0

Version Upgrade from 1.0-2.0

NIST Mass Spectral Database of Common Compounds 9

NIST/EPA/MSDC Mass Spectral Database(tape) 1

NIST Chemical Thermodynamics 2

$\begin{array}{ll}\text { NIST Supertrapp } & 19\end{array}$

Supertrapp Source 1

NIST Electron and Positron Stopping Powers (EPSTAR) 14

NIST X-ray and Gamma-ray Attenuation (XGAM) 27

NIST X-ray and Gamma-ray Attenuation Coefficients of 1

Aqueous and Electrolyte Solutions (GAMPHI)

NIST Thermophysical Properties of Water 13

DIPPR Data Compilation of Pure Compound Prop. Version 5

Upgrade from Version 4-Version 5

$\begin{array}{ll}\text { Student DIPPR } & 13\end{array}$

NIST Thermophysical Properties of Fluids (MIPROPS) 9

NIST JANAF Thermochemical Tables 6

NIST Thermophysical Properties of Mixtures (DDMIX) 13

NIST Chemical Kinetics(Version 1.0) 39

NIST Chemical Kinetics(Version 2.0) 64

$\begin{array}{ll}\text { Upgrade } 1.0-2.0 & 107\end{array}$

NIST Estimation of Thermodynamic..(THERM/EST) 10

NIST Positive and Negative Ion Energetics 50

NIST X-ray Photoelectron Spectroscopy 115 
NIST Thermodynamic Properties of Refrigerants and

Refrigerant Mixtures

NIST Atomic Transition Probabilities

NIST Vibrational and Electronic Energy Levels

\title{
Number of Databases Sold *
}

1987

1988

1989

1990
75

187

444

874

*Additional databases are distributed by other groups and their totals are not included in these figures.

\author{
Distributorships \\ January-December 1990 \\ NIST/EPA/MSDC Mass Spectral Database Tape 817 \\ NIST/EPA/MSDC Mass Spectral PC 30
}

Journal of Physical and Chemical Reference Data Publications in 1990 Volume 19

№.1

Chemical Kinetic Data Base for Combustion Chemistry. Part 4. Isobutane Wing Tsang

Thermodynamic Functions and Properties of $\mathrm{MgO}$ at High Compression and High Temperature Orson L. Anderson and Keshan Zou

Critical Compilation of Surface Structures Determined by Ion Scattering Methods Philip R. Watson

Benzene: A Further Liquid Thermal Conductivity Standard M.J. Assael, M.L.V. Ramires, C.A. Nieto de Castro, and W.A. Wakeham 
Energy Levels of Atomic Aluminum with Hyperfine Structure

Edward S. Chang

Spectral Data and Grotrian Diagrams for Highly Ionized Iron, Fe IV-XXVI

Toshizo Shirai, Yoshio Funatake, Kazuo Mori, Jack Sugar,

Wolfgang L. Wiese, and Yohta Nakai

Updated Excitation and Ionization Cross Section for Electron Impact on Atomic Oxygen

Russ R. Laher and Forrest R. Gilmore

№.2

Standard Chemical Thermodynamic Properties of Isomer Groups of Monochloroalkanes Robert A. Alberty and Michael B. Chung

Standard Chemical Thermodynamic Properties of Polycyclic Aromatic Hydrocarbons and Their Isomer Groups. III. Naphthocoronene Series, Ovalene Series, and First Members of Some Higher Series.

Robert A. Alberty, Michael B. Chung, and Andrea K. Reif

The Dielectric Constant of Water and Debye-Huckel Limiting Law Slopes

Donald G. Archer and Peiming Wang

Rate Constants for Reactions of Peroxyl Radicals in Fluid Solutions

P. Neta, Robert E. Huie, and Alberta B. Ross

No. 3

Energy Levels of Copper, Cu I through $\mathrm{Cu}$ XXIX

Jac. „ugar and Arlene Musgrove

Cross Sections and Related Data for Electron Collisions with Hydrogen Molecules and Molecular Ions

H. Tawara, Y. Itikawa, H. Nishimura, and M. Yoshino

Cross Sections for Collisions of Electrons and Photons with Atomic Oxygen

Y. Itikawa and A. Ichimura

Cross Sections End Swarm Coefficients for $\mathrm{H}^{+}, \mathrm{H}_{2+}, \mathrm{H}_{3+}, \mathrm{H}, \mathrm{H}_{2}$, and $\mathrm{H}^{-}$, in $\mathrm{H}_{2}$ for Energies from $\therefore \mathrm{eV}$ to $10 \mathrm{keV}$

A. Ir elps

Refractive Inc

Density

P. Schies...., J. Straub, J.M.H. Levelt Sengers, and J.S. Gallagher

Heat Capacities of Organic Compounds in the Liquid State I. $C^{1}$ to $C_{18} 1$-Alkanols Milan Zabransky, Vlastimil Ruzicka Jr., and Vladimir Majer 
The Transport Properties of Carbon Dioxide

V. Vesovic, W.A. Wakeham, G.A. Olchowy, J.V. Sengers,

J.T.R. Watson, and J. Millat

No. 4

Energy Levels of Sulfur, S I Through S XVI

W.C. Martin, Romuald Zalubas, and Arlene Musgrove

Heat Capacities and Entropies of Organic Compounds in the Condensed Phase, Volume II

Eugene S. Domalski and Elizabeth D. Hearing

The Thermodynamics of the Krebs Cycle and Related Compounds

Stanley L. Miller and David Smith-Magowan

No. 5

Transport Properties of Fluid Oxygen

A. Laesecke, R. Krauss, K. Stephan, and W. Wagner

Thermal Conductivity of Nine Polyatomic Gases at Low Density

F.J. Uribe, E.A. Mason, and J. Kestin

Thermal Conductivity of Methane and Tetrafluoromethane in the Limit

of Zero Density

M.J. Assael, J. Millat, V. Vesovic, and W.A. Wakeham

Coupled Phase Diagram - Thermodynamic Analysis of the 24 Binary Systems, $\mathrm{A}_{2} \mathrm{CO}_{3}$ $\mathrm{AX}$ and $\mathrm{A}_{2} \mathrm{SO}_{4}-\mathrm{AX}$ Where $\mathrm{A}=\mathrm{Li}, \mathrm{Na}, \mathrm{K}$ and $\mathrm{X}=\mathrm{Cl}, \mathrm{F}, \mathrm{NO}_{3}, \mathrm{OH}$

Yves Dessureault, James Sangster, and Arthur D. Pelton

Equilibrium and Transport Properties of Gas Mixtures at Low Density: Eleven Polyatomic Gases and Five Noble Gases

J. Bzowski, J. Kestin, E.A. Mason, and F.J. Uribe

A Unified Equation of State for Thermodynamic Properties of $\mathrm{H}_{2} \mathrm{O}$ Philip G. Hill

№. 6

The Viscosity and Thermal Conductivity of Pure Monatomic Gases from Their Normal Boiling Point up to $5000 \mathrm{~K}$ in the Limit of Zero Density and at $0.101325 \mathrm{MPa}$

E. Bich, J. Millat, and E. Vogel

Experimental Start Widths and Shifts for Spectral Lines of Neutral and Ionized Atoms (A Critical Review of Selected Data for the Period 1983 through 1988)

N. Konjevic and W.L. Wiese

Vibrational and Electronic Energy Levels of Polyatomic Transient Molecules. Supplement 1

Marilyn E. Jacox 
Thermodynamic and Thermophysical Properties of Organic Nitrogen Compounds. Part I. Methanamine, Ethanamine, 1- and 2-Propanamine, Benzenamine, 2-, 3-, and 4Methylbenzenamine

J. Chao, N.A.M. Gadalla, B.E. Gammon, K.N. Marsh,

G.R. Somayajulu, and R.C. Wilhoit

\section{Other Publications in the NIST Series}

NIST Standard Reference Data Products 1990 Catalog, NIST Special Publication 782 Malcolm W. Chase, Jr., editor

Multiphoton Bibliography 1987-1988, NBS-LP-92 Supp. 6

S.J. Smith, J.H. Eberly, and J.W. Gallagher, editors

Bibliography and Current Status of K, L, and Higher Shell Fluorescence Yields for Computation of Photon Energy-Absorption Coefficients, NISTIR 89-4144 (1989) J.H. Hubbell

\section{Data Compilations from Other Publishers}

Phase Diagrams for Ceramists, Volume 8, The American Ceramic Society, Columbus, $\mathrm{OH}, 399 \mathrm{p}$.

Nonequilibrium Effects in Ion and Electron Transport-Jean W. Gallagher, David F. Hudson, Erich E. Kunhardt, and Richard J. Van Brunt (editors), Plenum Press, NY, $464 \mathrm{p}$.

Lecture Notes in Physics - Accuracy of Element Abundances from Stellar Atmospheres-R. Wehrse, W.L. Wiese, and J.R. Fuhr (editors), No. 356, SpringerVerlag, Berlin, 12 p. (1990).

Atomic Transition Probabilities in CRC Handbook of Chemistry and Physics, 7lst edition, D.R. Lide (editor), CRC Press Inc., Boca Raton, FL, 51 p. (1990).

The Effect of Revisions of Debye-Huckel Limiting Law Slopes on the Thermodynamic Parameters for Strong Electrolyte Solutions-Donald G. Archer. J. Chem Eng. Data. 35,340 (1990).

The Kirkwood Equation Representation of the Static Dielectric Constant of WaterDonald G. Archer, Peiming Wang, and David B. Neumann in Properties of Water and Steam (M. Pichal, O. Sifner, ed., Hemisphere Publishing, NY, 1990.

A New Critical Review of Experimental Stark Widths and Shifts-W.L. Wiese and $N$. Konjevic, in Spectral Line Shapes, Vol. 6, (Ed. L. Frommholt), in press, 1990.

Atomic Transition Probabilities-W.L. Wiese, in Reports on Astronomy, Vol. XXIA, Reidel Publishing Co., Dordrecht, Holland (in press).

Progress of Atomic Transition Probabilities-W.L. Wiese, in The Physics of Ionized Gases (Ed. D. Veza), Nova Science Publ. NY (1990). 
Bremstrahlung Production by Electrons: Cross Sections and Electron-photon Transport Calculations High-Energy Radiation Background in Space (Eds. A.C. Rester and J.I. Trambka). AIP Conference Proceedings 186, AIP, NY (1989), PP. $103-124$.

X-Ray Absorption (or attenuation) Coefficients-D.C. Creagh and J.H. Hubbell, Section 4,2,4 in International Tables for Crystallography (in press).

Problems Associated with the Measurement of X-Ray Attenuation

Coefficients: Report on the IUCr x-ray attenuation project. II. Carbon, Acta Cryst. A. (in press).

Average L-shell Fluorescence Yields for Elements $56<\mathrm{Z}<92-\mathrm{S}$. Singh, D. Mehta, R.R. Garg, S. Kumar, M.L. Garg, N. Singh, P.C. Mangal, J.H. Hubbell, and P.N. Trehan, Nucl. Instr. Meth. B (in press).

Report to the International Astronomical Union Commission 14, Atomic and Molecular Data. Part 3. Collisional Cross Sections-J.W. Gallagher, Transactions of the International Astronomical Union (1990).

Biweekly List of Papers on Radiation Chemistry and Photochemistry, Annual Cumulation with Keyword and Author Indexes, Vol. 23, 1990-Rad. Chem. 23, Notre Dame, IN, Radiation Chem. Data Center, U. of Notre Dame, 32 p. (1990).

Biweekly List of Papers on Radiation Chemistry and Photochemistry, Annual Cumulation with Keyword and Author Indexes, Vol. 23, 1990-Rad. Chem. 23, Notre Dame, IN, Radiation Chem. Data Center, U. of Notre Dame, 490 p. (1990).

Mossbauer Effect Reference and Data Journal, V.E. Stevens, M.A. Goforth, V.L. Coman, C.R. Boss (editors), Moss. Effect Ref. Data J., Vol. 13, Asheville, NC: Moss. Effect Data Center, U. of NC (1990).

"Crevice Corrosion Testing in Natural Seawater: Significance and Use of Multiple Crevice Assemblies," R. M. Kain, ASTM Journal of Testing and Evaluation, Vol. 18, pp. 309-318 (1990).

"Phase Diagrams for Ceramists - Volume 8," Bjorn 0. Mysen, ed., (American At Ceramics Society, Westerville, OH, 1990).

"Phase Diagrams for Ceramists - Bibliographic Update and Cumulative Indexes," M. A. Clevinger, K. M. Kessell, C. G. Messina, and H. M. Ondik (American Ceramics Society, Westerville, OH, 1990).

"Binary Alloy Phase Diagrams, Second Edition, Three volumes," T. H. Massalski, Editor in Chief (ASM International, Metals Park, OH, 1990). 
Thermodynamic Data for Iron from 200 to $3000 \mathrm{~K}$ and from 0 to $200 \mathrm{KBAR}$

John L. Haas, Jr. and Malcolm W. Chase, Jr.

Aqueous Solubility of Organic Chemicals: A Compilation of Experimental Data, Correlations and Predictive Models

N. Nirmalakhandan and R.E. Speece

Spectroscopy and Structure of the Alkali Hydride Diatomic Molecules and Their Ions

William C. Stwalley, Warren T. Zemke, and Sze Cheng Yang

Critical Evaluation of Liquid Crystal Transition Temperatures I: 4,4' -Alkyl/Alkoxyphenylbenzoates

Terence T. Blair, Mary E. Neubert, Mitchell Tsai, and Chun-che Tsai

Critical Compilation of Physical Properties of Short-Lived Intermediates:Carbenes and Carbene Analogues

O.M. Nefedov, M.P. Egorov, A.I. Ioffe, L.G. Menchikov,

P.S. Zuev, N.D. Zelinsky, V.I. Minkin, B.I. Simkin,

M.N. Gluchovtsev

Heat Capacity and Other Thermodynamic Properties of Linear Macromolecules X. Update of the ATHAS 1980 Data Bank

Manika Varma-Nair and Bernhard Wunderlich

Heat Capacities of Basic Organic Compounds in Liquid State II. Cl to C18 $\mathrm{N}$ Alkanes

Vlasí.mil Ruzicka, Jr., Milan Zabransky, and Vladimir Majer

Spectral Data and Grotrian Diagrams for Highly Ionized Copper,

$\mathrm{Cu} \mathrm{X}$ - Cu XXIX

Toshizo Shirai, Toshiaki Nakagaki, Yohta Nakai, Jack Sugar,

Keishi Ishii, and Kazuo Mori

Kinetics and Mechanisms of the Gas-Phase Reactions of the $\mathrm{NO}_{3}$ Radical With Organic Compounds

Roger Atkinson

Thermodynamic Properties of the $\mathrm{NaBr}+\mathrm{H}_{2} \mathrm{O}$ System Donald G. Archer

Chemical Kinetic Data Base for Combustion Chemistry Part V: Propene Wing Tsang

Chemical Kinetic Data Base for Propellant Combustion: I: Reactions Involving NO, $\mathrm{NO}_{2}, \mathrm{HCN}$ and $\mathrm{N}_{2} \mathrm{O}$

Wing Tsang and John T. Herron 
Wavelengths and Energy Level Classifications of Magnesium Spectra for All Stages of Ionization ( $\mathrm{Mg}$ I through $\mathrm{Mg}$ XII)

Victor Kaufman and W.C. Martin

Solubilities of Solids and Liquids of Low Volatility in Supercritical Carbon Dioxide

K.D. Bartle, A.A. Clifford, S.A. Jafar, and G.F. Shilstone

A Fundamental Equation and Tables of Thermodynamic Properties for

Methane Covering the Range from the Melting Line to $623 \mathrm{~K}$ at Pressures up to 1000 $\mathrm{MPa}$

U. Setzmann and W. Wagner

Thermodynamic Properties of the Aqueous Sulfuric Acid System to $350 \mathrm{~K}$

F.J. Zeleznik

Statistical Thermodynamic Properties of the Fluorobenzenes

J.A. Draeger and P.J. Farris, Jr.

Thermodynamic Properties of Oxygen from the Triple Point to $300 \mathrm{~K}$ with Pressures to 80 MPA

Richard B. Stewart, Richard T. Jacobsen, and W. Wagner

Evaluation of Solubility Data of the System $\mathrm{CO}_{2}-\mathrm{H}_{2} \mathrm{O}$ from $273 \mathrm{~K}$ to the Critical Point of Water

Rosa Crovetto

Ab-Initio Calculations and Ideal Gas Thermodynamic Functions of Cyclopentadiene Radicals

Miriam Karni, Izhack Oref, and Alexander Burcat

Chemical Kinetic Data Sheets for High-Temperature Reactions. Part II

N. Cohen and K.R. Westberg

Improved Fits for the Vibrational and Rotational Constants of Many States of Nitrogen and Oxygen

Russ R. Laher and Forrest R. Gilmore

Evaluated Kinetic Data for Combustion Modelling

D.L. Baulch, C.J. Cobos, R.A. Cox, P. Frank, T. Just,

J.A. Kerr, M.J. Pilling, J. Troe, R.W. Walker, J. Warnatz 
The numeric data programs and their major FY 1990 accomplishments are listed in the following pages. The data centers are listed first, followed by the data projects and grants. For the data centers, a brief description of the objectives of the center is given also. In all cases, SRD money is used to fund their activities (although these centers typically have other sources of support). The data center and data project activities are discussed in more detail in the NIST Technical Activities Reports of the respective divisions in which the center/project organizationally resides.

\section{NIST/ASM ALLOY PHASE DIAGRAM PROGRAM}

Director: E. Neville Pugh

Institute for Materials Science and Engineering, NIST

The NIST/ASM Alloy Phase Diagram Program has been a long-term effort to completely reevaluate all binary alloy phase diagrams and to formulate an international cooperative program for evaluating ternary and higher order diagrams.

NIST is responsible for the technical content and editing of the Bulletin of Alloy Phase Diagrams, a joint bimonthly publication with ASM International. The Editor of the Bulletin is Prof. Jack Smith of Iowa State University. The Bulletin has become the prime source of evaluated phase diagrams. Computer graphics software for phase diagrams was developed by NIST and is used by ASM to help produce the Bulletin.

Several monographs on individual binary systems have been published, some of these the result of work by NIST scientists.

\section{AQUEOUS ELECTROLYTE DATA CENTER}

Director: David B. Neumann

Center for Chemical Technology, NIST

The Aqueous Electrolyte Data Center (ELDC) serves as a national and international source of critically evaluated chemical thermodynamic data for aqueous electrolyte systems. It provides temperature, pressure, and concentrationdependent data on activity and osmotic coefficients and excess thermodynamic properties of aqueous salts and salt mixtures. Such data are required in the analysis of chemical and biochemical equilibria and are crucial to the computer simulation of chemical processes occurring in a variety of areas ranging from geology to chemical engineering to biotechnology.

Among the significant accomplishments during the past year are: development of the computer code required to fit experimental measurements over wide ranges of $T, P$, and $x$; expansion of the capabilities of the PC version of the Aqueous Thermodynamics Database to accommodate $\mathrm{E}^{\circ}$-pH diagrams; expansion of the capabilities of the GAMMIX program for the calculation of activity and osmotic coefficients. This PC database is planned for a FY 1991 release. 
Papers published in FY 1990 are:

(1) D.G. Archer and P. Wang, The Dielectric Constant of Water and Debye-Huckel Limiting Law Slopes, J. Phys. \& Chem. Ref. Data 19, 371-411 (1990).

(2) D.G. Archer, Effect of Revisions of Debye-Huckel Limiting Law Coefficients on the Thermodynamic Parameters for Strong Electrolyte Solutions, J. Chem. Eng. Data 35, 340-344 (1990).

Papers in review are:

(1) D.G. Archer, Thermodynamic Properties of the $\mathrm{NaBr}+\mathrm{H}_{2} \mathrm{O}$ System, J. Phys. \& Chem. Ref. Data 20, (in review) 1991.

(2) C. Li and D.G. Archer, E-pH AID Program for the Calculation of Predominance Diagrams, User's Manual (in review) 1991.

\section{ATOMIC COLLISION CROSS SECTION DATA CENTER}

Director: John Broad

Joint Institute for Laboratory Astrophysics

University of Colorado, Boulder, Colorado

The purpose of the JILA data center is to compile and evaluate data describing non-reactive collisions of electrons and photons with atoms, ions, and simple molecules and of low-energy non-reactive atom-atom and ion-atom collisions.

Major changes in the staff of the data center were made during the past year. Dr. John Broad, a theoretical chemist from the Albert-Ludwigs-Universitat in Freiberg became Director in October, 1990. Pat Ruttenberg who had been a Computer Specialist at the data center for over 20 years retired in April, 1990. Patti Krog who designed and implemented some of the PC software left in September, 1990. Steven Krog will remain but take on new responsibilities associated with the new computer system.

Utilizing a generous grant from the Department of Energy matched by NIST depreciable equipment funds, a DEC workstation and appropriate peripherals were purchased to replace the Cyber mainframe as the home for the Atomic Collisions Database and to be used as the device to execute future projects. Transferring the database and redesigning it for the new environment is a major task scheduled for the coming year.

Various publications were completed:

(1) The comprehensive review article "Cross Sections and Swarm Coefficients for $\mathrm{H}^{+}, \mathrm{H}_{2}{ }^{+}, \mathrm{H}_{3}{ }^{+}, \mathrm{H}, \mathrm{H}_{2}$, and $\mathrm{H}^{-}$in $\mathrm{H}_{2}$ for Energies from $0.1 \mathrm{eV}$ to $10 \mathrm{keV}$ " by A. V. Phelps was published [J. Phys. Chem. Ref. Data 19, 653 (1990)].

(2) The Multiphoton Bibliography 1987-1988, S. J. Smith, J. H. Eberly, and J. W. Gallagher [NBS LP-92, Supp. 6, June 1990] which is a continuation and expansion of the existing collection of references describing studies of the 
interaction of more than one photon with individual atoms and molecules in the gas phase was completed.

(3) The "Bibliography of Electron Swarm Data" by W. Lowell Morgan covering published data on the transport properties of electron swarms in gases and cross section information derived therefrom during the period from 1979 to mid-1989 was completed.

(4) Work continued on the second part of the review series "Collisional Alignment and Orientation in Atomic Outer Shells. II. Quasimolecular Excitation. N. Andersen, E. Campbell, J. W. Gallagher, I. V. Hertel.

\section{ATOMIC ENERGY LEVELS DATA CENTER}

Director: William C. Martin

Center for Atomic, Molecular, and Optical Physics, NIST

The Center compiles, evaluates, and disseminates data on energy levels and spectral lines of atoms and atomic ions. Reliable atomic spectroscopic data are essential in such areas as plasma diagnostics, laser physics, and astronomy.

The following evaluated compilations have been published in the Journal of Physical and Chemical Reference Data:

- "Spectral Data and Grotrian Diagrams for Highly Ionized Iron, Fe VIIIXXVI," T. Shirai, Y. Funatake, K. Mori, J. Sugar, W. L Wiese, and Y. Nakai, J. Phys. Chem. Ref. Data 19, 127-275 (1990).

- "Energy Levels for Copper, Cu I through Cu XXIX," J. Sugar and Arlene Musgrove, J. Phys. Chem. Ref. Data 19, 527-616 (1990).

- "Energy Levels of Sulfur, S I through S XVI," W. C. Martin, R. Zalubas, and A. Musgrove, J. Phys. Chem. Ref. Data 19, $821-880$ (1990).

- "Wavelengths and Energy Level Classifications of Magnesium Spectra for All Stages of Ionization, (Mg I through Mg XII," V. Kaufman and W. C. Martin, J. Phys. Chem. Ref. Data 20, 83-152 (1991).

Work continues on a compilation of wavelengths and energy levels classifications for cobalt spectra in collaboration with workers from the Japan Atomic Energy Research Institute (Ibaraki) and the Institute of Plasma Physics (Nagoya) in Japan.

Plans for FY 1991 include publication of compilations of energy-level data for all krypton spectra ( $\mathrm{Kr} I$ through XXXVI) and germanium spectra (Ge I through $\mathrm{Ge}$ XXXII) and completion of wavelength compilations with energy-level classifications for all spectra of the elements silicon and aluminum. Work will beg: on compiling energy levels for chlorine.

Much of the development of an Atomic Spectroscopy Database including capability for storage and retrieval of atomic line classifications, transi- 
tion probabilities, transition wavelengths, and energy levels has been completed. Energy levels have been loaded for elements with the following atomic numbers: $Z=2,11-16,19-29,36,42,57-71$. Wavelengths have been loaded for $\mathrm{Z}=12$ and 21 . Transition probabilities have been loaded for the iron group elements: $Z=21-28$.

\section{ATOMIC TRANSITION PROBABILITIES DATA CENTER}

Director: Wolfgang L. Wiese

Center for Atomic, Molecular, and Optical Physics, NIST

The Center's purpose is to compile, evaluate, and disseminate data on radiative transition probabilities for atoms and atomic ions. These data are essential in such areas as plasma modeling and analysis, including fusion research, as well as laser physics and astrophysics.

Data from the two-volume series "Transition Probabilities for Scandium Through Nickel" were made available on PC diskette as NIST Standard Reference Database 24.

A bibliographical database on transition-probability literature has been developed and several hundred literature references have been entered into this system.

Much of the development of the numerical Atomic Spectroscopy Database, including capability for storage and retrieval of atomic line classifications and energy levels, has been completed. Work continues on capability for entry and retrieval of wavelengths and transition probabilities. Transition probabilities have been loaded for the iron group elements:

atomic number $(Z)=21-28$. Energy levels have been loaded for elements with the following atomic numbers: $Z=2,11-16,19-29,36,42,57-71$. Wavelengths have been loaded for $\mathrm{Z}=12$ and 21 .

A book chapter entitled "On the Accuracy of Atomic Transition Probabilities" was completed for publication in the Springer Verlag series Lecture Notes in Physics.

During FY 1990 work started on critical evaluation of the transition probabilities of the 10 lightest elements (hydrogen through neon). As part of this effort, evaluation of high-accuracy calculated transition probabilities from the Opacity Project was started. Selected data from this source will eventually be incorporated into the NIST Atomic Spectroscopy Database. Due to newly available results, new evaluations of $\mathrm{Mo}, \mathrm{Ba}$, and $\mathrm{Hg}$ are also in progress.

\section{STRUCTURAL CERAMICS DATA CENTER}

Director: Ron Munro

Laboratory of Materials Science and Engineering, NIST

A computerized database on silicon carbides and silicon nitrides has been built and released by this data center. The data have come from over 30 journals and reports and have been evaluated by NIST experts. This is the first structural ceramics database publicly available. 
The data center plans to update the database adding to it data from several large computerized collections. In addition, the center is beginning work on a possible expert system related to the use of these data in design.

\section{CHEMICAL KINETICS DATA CENTER}

Director: John T. Herron

Center for Chemical Technology, NIST

The goal of the Chemical Kinetics Data Center is to serve as the nation's primary source for evaluated chemical kinetic data. The emphasis is on gas phase processes for which there is a demonstrated need. The approach is to compile all data on gas phase chemical kinetics, and to evaluate specific subsets of this general database. This allows us to concentrate our efforts on those areas of greatest practical interest, while maintaining the ability to move rapidly into new evaluation activities as the need arises. The evaluated and unevaluated databases are also available to outside users.

Evaluated chemical kinetic data are most needed in those areas of science and technology in which computer simulation studies are being used to predict the behavior of large-scale, complex chemical systems. Thus, the focus of our evaluation program is in the area of the oxidation of organic compounds, particularly as related to combustion and atmospheric chemistry. This also constitutes the largest active area in experimental chemical kinetics.

Activities over the past year include:

- continued expansion of the evaluated chemical kinetic database for combustion chemistry.

- extension of the original data for methane to include methanol, $C_{3}$ alkanes and alkyl radicals, and $C_{4}$ alkanes and alkyl radicals. A series of publications are appearing in JPCRD (W. Tsang, Chemical Kinetic Data Base for Combustion Chemistry. Part 3. Propane," J. Phys. Chem. Ref. Data 17, 887 (1988).

- continued support for the NASA stratospheric chemistry program, with evaluation activities in the area of halogen chemistry (in conjunction with the NASA Panel for Data Evaluation and the IUPAC Subcommittee on Gas Kinetic Data Evaluation for Atmospheric Chemistry).

- analysis of dielectric breakdown and chemical vapor deposition (plasma chemistry) with consideration of the thermal stability of sulfur hexafluoride and disulfur decafluoride. The design of a database of evaluated data on reactions in the $\mathrm{SF}_{6} / \mathrm{O}_{2} / \mathrm{H}_{2} \mathrm{O}$ system has been completed.

- an important accomplishment of FY 1990 has been the completion and release for sale of the PC Version 2.0 of the NIST Chemical Kinetics Database. This database has been expanded and is of high interest within the field of chemical kinetics and related applied areas. A highly interactive program allows the user to search by reactants or by reference. The database contains more than 2400 chemical species and 12,000 records. 
The compilation of chemical kinetic data continues to grow from evaluated sets of data and from published research articles. The bibliography for the kinetics database extends into 1990.

\section{CHEMICAL THERMODYNAMICS DATA CENTER}

Director: Eugene S. Domalski

Center for Chemical Technology, NIST

The Center provides the chemical process industry and related industries with critically evaluated thermodynamically consistent data which can be used to establish the equilibrium constants and enthalpies of reaction for important chemical reactions. These critically evaluated data also are used in the design and interpretation of research in physics, chemistry, biochemistry, geochemistry, environmental sciences, metallurgy, and other fields where chemical interactions are important. Research projects in the Center focus on the thermodynamic properties of both inorganic and organic compounds.

The Center surveys the thermodynamic literature and extracts pertinent data with particular emphasis on the active research projects rather than the entire scope of all available thermodynamic property information.

\section{Inorganic Thermochemistry}

Thermodynamic properties of selected chemical elements are being studied for the JANAF Thermochemical Tables project. The initial bibliographic portion of this effort has been completed. The data collection and evaluation process is nearing completion. In addition, for the JANNAF Subcommittee on Combustion, the study of the thermodynamic properties of many gaseous species containing the elements $\mathrm{C}, \mathrm{H}, \mathrm{N}$, and $\mathrm{O}$ has been completed. A similar study for NASA is in progress on gaseous chlorine oxides, oxy-halogen acids, and related species.

The Center is cooperating through CODATA with other centers located in Europe and the United States to develop thermodynamic tables for iron and its compounds. A similar effort was begun to develop thermodynamic tables for yttrium and its compounds.

\section{Organic Thermochemistry}

Continued progress was made in developing schemes for the estimation of the heat capacity, entropy, and formation properties at $298.15 \mathrm{~K}$ for species of the type $\mathrm{C}-\mathrm{H}, \mathrm{C}-\mathrm{H}-\mathrm{O}, \mathrm{C}-\mathrm{H}-\mathrm{N}$, and $\mathrm{C}-\mathrm{H}-\mathrm{N}-\mathrm{O}$ in the crystal, liquid, and gaseous states. During FY 1990, a paper appeared in JPCRD entitled: "Heat Capacities and Entropies of Organic Compounds in the Condensed Phase. Volume II". During FY 1991, papers on the estimation of the thermodynamic properties of $\mathrm{CHO}$, CHN, and CHNO compounds are planned for submission to JPCRD. 
Director: David B. Anderson

Institute for Materials Science and Engineering, NIST

The Corrosion Data Center provides scientific and technical coordination to the joint program between the National Association of Corrosion Engineers (NACE) and NIST. The program objective is to enhance the availability of corrosion information through collection, evaluation, and dissemination of performance data on engineering materials exposed to a wide variety of corrosive environments. A key activity is establishment of an evaluated database to serve as the basis for a series of distributed software addressing specific industrial needs.

Three databases have been completed and are being marketed by NACE. Two are based on published compilations for both metals and nonmetals. The third is a database package to handle a wide variety of corrosion field test and laboratory data. Software is also in development for calculation and display of potential $\mathrm{pH}$ stability diagrams in a simplified PC format. Efforts in conjunction with key NACE and ASTM task groups have led to a basis for standardization of corrosion data formats compatible with database management needs for data capture and structuring search strategies to support a diverse user base. The formats will also assure compatibility with other material property databases currently under development.

Multiple data sources have been identified, and programs are underway to capture and compile data for introduction into a centralized database. Efforts have also been initiated, supported by a second NACE Research Associate, to develop expert system modules for materials selection for process and storage equipment with applications in key sectors of the chemical industry. Several modules on materials for handling and storing various industrial acids are available.

\section{CRYSTAL AND ELECTRON DIFFRACTION DATA CENTER}

Director: Alan D. Mighell

Institute for Materials Science and Engineering, NIST

The NIST Crystal and Electron Diffraction Data Center collects, evaluates, and disseminates data on solid-state materials. The Data Center maintains a comprehensive database for chemical, physical, and crystallographic information on all types of well characterized substances. Data and specially designed scientific software are made available to the scientific community in three distinct modes: 1) NIST CRYSTAL DATA Distribution Package; 2) International Online Search System; and 3) Specialized Database for Electron Diffractionists.

The first product is NIST CRYSTAL DATA, a FORTRAN program (NIST* SEARCH), and accompanying documentation. NIST CRYSTAL DATA contains up-to-date crystallographic data on more than 115,000 materials. Each entry consists of the reduced cell and volume, crystal system, space group symbol and number, chemical name, chemical formula, literature reference, and other data. NIST*SEARCH software has been designed to be used for the characterization and identification of crystalline materials. 
The NIST Crystal Data Center and CISTI's CAN/SND Scientific Numeric Database Service (Canada) collaborate to make the data available through CRYSTDAT. CRYSTDAT is an online, state-of-the-art database search system that can easily be accessed by scientists worldwide.

A second product, designed specifically for electron diffractionists, is now available. This product allows the experimentalist to identify materials using such typical electron diffraction data as elemental information and dspacings. The database for electron diffraction was prepared in three basic steps. To generate this derivative database, d-spacings ( 3.6 million) were calculated for all inorganic compounds in NIST CRYSTAL DATA using cell and space group information. These data were then combined with similar data on 10,000 entries from the Powder Diffraction File. Extensive tests using observed electron diffraction data have proved that the database provides a major new analytical tool for electron diffractionists. The generation of this new product was carried out as a collaborative effort between the NIST Crystal Data Center and Dr. Martin Carr of the Sandia National Laboratories.

\section{FLUID MIXTURES DATA CENTER}

Director: James F. Ely

Center for Chemical Technology, NIST

The Center is organized to compile and evaluate data on the thermodynamic and transport properties of fluids and fluid mixtures. These properties include formulations for the density and other thermodynamic properties of pure fluids, the viscosity and thermal conductivity of pure fluids, and the same properties for fluid mixtures. The Center is also involved with the development of techniques to predict transport properties of pure fluids from thermodynamic and molecular data, to predict properties of mixtures from the properties of pure fluids, and to interpolate and extrapolate data for properties over wide ranges of temperature, pressure, and--in the case of the mixtures--mole fractions. A strong element in all of the work is the production of computerized databases which are then disseminated by SRD and other organizations.

The computer package MIPROPS is being distributed by SRD and is available through the on-line services of CAS/STN. The DDMIX computer package, after undergoing substantial technical and software changes, also is available for distribution through SRD. DDMIX has been valuable to industry in the contractual custody transfer of carbon-dioxide-rich mixtures and in engineering design. Upon completion of major improvements in the transport property theoretical model, SUPERTRAPP has been delivered to SRD for testing.

The analysis of the thermodynamic properties of methanol, benzene, and toluene has been completed. While the methanol paper has already been published, the other two contributions are in the review process. In addition, a critical evaluation on the properties of ethane is scheduled to appear in JPCRD in 1991 while a similar work on propane is near completion. 
Director: Bar; N. Taylor

Center for Atowic, Molecular \& Optical Physics, NIST

The Data Center carries out least-squares adjustments of the fundamental physical constants resulting in the international adoption of recommended sets of constants. The Center also provides a centralized source of information on the fundamental physical constants and on closely related precision measurements. It participates in the periodic development under the auspices of CODATA of sets of "best" or recommended values of the fundamental physical constants by means of least-squares adjustment.s. The self-consistent best values of the constants resulting from an adjustment are required for computational purposes and often are the basis for other data compilations. The Center also participates in the organization of conferences and/or sessions at conferences relating to the precision measurement-fundamental constants (PMFC) field; administers the NIST Precision Measurement Grant program; and participates in the work of various committees and organizations active in the PMFC field such as the NAS/NRC Advisory Committee on Fundamental Constants and Basic Standards, and the APS Topical Group on Fundamental Laws and Constants.

During 1990, several publications were completed:

- "Recommended Values of the Fundamental Physical Constants: A Status Report" (for the CODATA Task Group on Fundamental Constants), Barry N. Taylor and E. Richard Cohen, J. Res. Natl. Inst. Stand. Technol. 95, 497 (1990).

- "The Fine-Structure Constant," Barry N. Taylor, Units and Fundamental Constants in Physics and Chemistry, Landolt-Bornstein Numerical Data and Functional Relationship Series, Ed. by J. Bortfeldt and B. Kramer (Springer-Verlag, Berlin) (in press).

- "How Accurate are the Josephson and Quantum Hall Effects and QED?" Barry N. Taylor and E. Richard Cohen, Physics Letters A, (1991), submitted.

Articles on Fundamental Constants are being prepared for the Academic Press "Encyclopedia of Applied Physics and Science."

The Director of the Fundamental Constants Data Center, Dr. Barry N. Taylor, serves as Chief Editor of the NIST J. Res., Administrator of the NIST Precision Measurement Grants Program; and on several other national and international committees and boards.

\section{ION KINETICS AND ENERGETICS DATA CENTER}

Director: Sharon G. Lias

Center for Chemical Technology, NIST

The aim of the Data Center is to compile, evaluate, and disseminate data on ionization and appearance energies of ions from neutral precursor molecules, 
the enthalpies of formation of the resulting molecular and fragment ions, and on the rate constants for reaction of those ions with molecules.

A major publication of the data center, "Gas-phase Ion and Neutral Thermochemistry," by Sharon G. Lias (NIST), J. E. Bartmess (University of Tennessee), J. E. Liebman (University of Maryland Baltimore County Campus), J. L. Holmes (University of Ottawa), R. D. Levin (NIST), and W. G. Mallard (NIST) has appeared in JPCRD (J. Phys. \& Chem. Ref. Data 17, Supp1. No. 1, 1988). The publication gives evaluated enthalpies of formation of approximately 8000 ions ( 5600 cations and 2400 anions). Also, a computerized database is available which contains the comprehensive background data used in this JPCRD publication (NIST Standard Reference Database 19A, Positive Ion Energetics and 19B, Negative Ion Energetics).

Work on the update of the publication "Evaluated Gas Phase Basicities and Proton Affinities of Molecules: Heats of Formation of Protonated Molecules" has continued. The computer files have been reformatted preparatory to producing a PC version of the collection. The data are now being evaluated. Submission of a paper for JPCRD is planned at end of FY 1991.

\section{MOLECULAR SPECTRA DATA CENTER}

Director: Frank J. Lovas

Center for Atomic, Molecular, and Optical Physics, NIST

The Center provides for the collection, evaluation, and dissemination of molecular spectral frequencies and other molecular constants. Published reviews are designed to aid in the analysis and identification of compounds and to permit the determination, comparison, and derivation of a wide range of molecular properties. The molecular properties include energy levels, structures, molecular moments, and molecular constants needed to reproduce the spectra. One phase of the Center's work emphasizes microwave spectra of interstellar molecules for species identification, abundance determination, and molecular cloud properties such as temperature and velocity. The objective of this effort is to provide astronomers with a convenient source of molecular transitions previously identified in stellar and interstellar objects and to provide the most accurate measured or calculated transition frequencies available.

The second revision of "Recommended Rest Frequencies for Observed Interstellar Molecular Microwave Transitions" is nearing completion. Since the first revision was completed in 1986, 18 new interstellar species have been identified, bringing the total number of identified molecules to 77 . Many new transitions of the previously known species have also been reported, representing an approximate 20 percent increase in the amount of observational data.

Work continues on the Microwave Spectral Tables IV, which treats organic species containing oxygen. The collection currently includes 171 species with empirical formulas $\mathrm{CHO}$ through $\mathrm{C}_{7} \mathrm{H}_{12} \mathrm{O}$, and plans are for publication of this massive amount of material as a three-part series. To develop these tables, data from various spectral observations are fitted to the appropriate Hamiltonian to verify the accuracy of frequency measurements and assigned quantum numbers. In many cases, the spectral lines for many normal isotopic species are refit to produce a comprehensive and consistent analysis of all the data extracted from 
various literature sources. Molecular properties, such as rotational and centrifugal distortion constants, hyperfine structure constants, electric dipole moments, and rotation $g$-factors, are derived. So far, spectral data for 68 species ( 375 isotopic forms) have been coded for spectral fitting and tablegenerating programs. The associated files, containing about 20,000 entries, are much larger than similar ones developed for simple hydrocarbons. Part A of the three-part series which will include approximately 45 species is scheduled for completion late in 1991, and simultaneously, work will be started on Part B of the series.

\section{MOLTEN SALTS DATA CENTER}

Director: George J. Janz

Rensselaer Polytechnic Institute

Troy, New York

The Center compiles, evaluates, and disseminates data on thermophysical properties of molten salt systems. Properties covered include density, electrical conductivity, viscosity, surface tension, and selected thermodynamic properties including the eutectic points of mixtures. Broadly, the aims encompass the development of standard reference data for molten salts physical properties from studies of the results in the open scientific literature, through critical evaluations and value judgments. Preparation of the results of these studies of best values and products for users as authoritative compilations of best values and data for comparison purposes are part of this program.

For the past year, SRD's effort has principally focused on critical data evaluations, extending the studies to newly reported systems and to database automation. Briefly, some of the activities include development of a compilation of correlation equations for the critically evaluated properties, enhancement of the automation of the MSDC-RPI database, and evaluation of some corresponding states data correlations as predictive models for molten salts transport properties. In addition, two NIST Standard Reference Databases are in prepara:ion: cra on the properties of single-phase molten salts and the other on molten salt mixtures.

\section{NATIONAL CENTER FOR THE THERMODYNAMIC DATA OF MINERALS}

Director: Bruce S. Hemingway

U.S. Geological Survey

Reston, Virginia

The Center compiles, indexes, and evaluates data on the thermodynamic and thermophysical properties of minerals, their synthetic analogues, and geologic materials. These data are important for geochemical purposes and useful industrially in the fields of metallurgy and the synthesis and production of inorganic chemicals.

In particular, the Center develops critically evaluated thermodynamic data for naturally occurring solid phases or their chemical end members. Properties considered are he c capacity, entropy, enthalpy, Gibbs energy, enthalpy and Gibbs energy of formation, molar volume, molar compressibility, and molar expansivity, all as functions of temperature, and phase diagrams of systems containing mineral 
phases. The Center cooperates closely with the Chemical Thermodynamics Data Center. The Center is also working with the CODATA Task Group on Chemical Thermodynamic Tables in their current work on iron and its compounds, especially in connection with the study of elemental iron and the oxides of iron.

\section{NIST MASS SPECTROMETRY DATA CENTER}

Director (Technical): Dr. Stephen E. Stein

Director (Administrative): Dr. Sharon G. Lias

Chemical Science and Technology Laboratory, NIST

This is a new Data Center, created in October, 1988, for the purpose of maintaining, updating, and improving the NIST/EPA/MSDC Mass Spectral Database. This computerized database of analytical mass spectra, originally developed 20 years ago by scientists at the EPA and NIH, has been distributed by the National Bureau of Standards since 1978. Until 1988 EPA had primary responsibility for maintenance of the database. Thousands of copies of the database are in use in the data systems of commercial mass spectrometers, and in a PC version developed at NIST. The database is released in a tape version, distributed mainly to instrument manufacturers who incorporate the database into the data systems of mass spectrometers, and a PC version for the use of individual bench scientists. The PC version with search software was developed at NIST in 1987.

An update of the database was released to the public in April, 1990. The database included 53,994 spectra, an increase of 4,525 over the previous version. The 1990 release also included structural information on more than 98 percent of the compounds in the database.

An additional release this year was the NIST Mass Spectral Database of Common Compounds. This PC database of 10,330 mass spectra was selected from the larger mass spectral database by taking spectra of all commercially available compounds, all compounds with molecular weights of $100 \mathrm{amu}$ or lower, and all important drugs and compounds appearing on EPA lists of pollutants. The software used for the Common Compounds database is identical to that used for the larger version of the database.

The initial examination by the NIST team of the database and the larger archive of spectra from which it is derived revealed that the spectra in the collection contained thousands of errors. An intensive effort was mounted to eliminate or correct erroneous spectra. Until such time as the database is error-free, work will continue on cleaning up the archive of spectra from which the database is drawn. At the present time, a spectrum-by-spectrum evaluation of 30,000 replicate spectra is nearly completed. The final product of this evaluation will be an auxiliary file of about 7,000 good quality replicate spectra which will be distributed with the database. A statistical study of retrieval rates for mass spectral databases has shown that the probability of retrieving a correct spectrum in a search is significantly enhanced when the database includes replicate spectra.

A high priority activity is the acquisition of new spectra to enlarge the database. Original spectra of widely-used commercially available compounds which are not now in the database are being obtained through outside contracts and by determining spectra inhouse. Also, several laboratories have donated original new spectra, and some other existing collections of spectra have been located in mass spectrometry laboratories, and will be purchased for the database. 
A by-product of the in-house determination of mass spectra is a collection of vapor phase infrared spectra. It is anticipated that within a year, a database of 8,000 spectra will be available for distribution. Software for presentation of this database has already been developed.

\section{PHASE DIAGRAMS FOR CERAMISTS DATA CENTER}

Director: Stephen Freiman

Institute for Materials Science and Engineering, NIST

The purpose of the Phase Diagrams for Ceramists Data Center is to support the rapidly growing ceramics industry with evaluated ceramic phase diagrams. These diagrams present the relationship of processing conditions (e.g., T, P, composition) to thermodynamic equilibria of phases (solid, liquid, or gaseous). All inorganic, nonmetallic systems are covered, including oxides, halides, sulfides, borides, carbides, nitrides, and semiconductors. These ceramic materials are used in a wide breadth of applications including structural, electronic, and optical, and they exhibit advantageous properties such as strength at high temperature, wear resistance, corrosion resistance, high and low dielectric constants, superconductivity, transmissivity, etc.

The long-range goals of the Data Center are threefold: (1) to develop a computerized database consisting of diagram graphics, keywords, critical evaluations, and the associated bibliography; (2) to expand the coverage to nonoxide systems and bring up to date the literature coverage, and (3) to disseminate the data to the user community in both computer and printed formats. To achieve these goals, NIST and the American Ceramic Society have established a cooperative program with additional support from industry and other Federal agencies.

The accomplishments of the cooperative program in the last year are succinctly summarized by the completion of Vol. 8 of Phase Diagrams for Ceramists. This volume contains more than 700 critical evaluations and 1000 individual diagrams and was produced entirely from the graphics, commentary, and bibliographic databases.

\section{PHOTON AND CHARGED PARTICLE DATA CENTER}

Director: Stephen M. Seltzer

Institute for Materials Science and Engineering, NIST

The Center compiles, evaluates, and disseminates data on the interaction of ionizing radiation with matter. The data on photons and charged particles include single-scattering cross sections as well as transport data pertaining to the penetration of radiation through bulk matter.

A comprehensive review of the fluorescence yield for all elements, $z=1$ to 100 , was prepared as a NIST Report entitled "Bibliography and Current Status of $K$, $L$, and Higher Shell Fluorescence Yields for Computation of Photon Energy-Absorption Coefficients," by J. H. Hubbell.

Electron and positron radiation yields needed for the calculation of bremsstrahlung factors in energy-absorption coefficients have been generated for some 28 materials of dosimetric interest and combined with the NIST database of photon cross sections (XGAM) to produce tables of the mass energy-transfer and mass-energy-absorption coefficients, from $10 \mathrm{keV}$ to $100 \mathrm{MeV}$, for the 28 materials. 
Tables of stopping powers (electronic, nuclear, and total), CSDA ranges, and projected ranges (penetration depths) have been prepared for protons with energies from $1 \mathrm{keV}$ to $10 \mathrm{GeV}$ and alpha particles with energies from $1 \mathrm{keV}$ to $1 \mathrm{GeV}$ in 73 materials of dosimetric interest.

The cross sections for elastic scattering of electrons have been accurately calculated using a partial-wave-expansion method for 11 kinetic energies from $1 \mathrm{keV}$ to $1 \mathrm{MeV}$, for the elements $\mathrm{Z}=1$ to 100 . The results have been organized into a computerreadable database. Plans for FY 1990 include expansion of this database by (1) performing additional calculations for electrons at low energies where the cross sections have complicated structures and the present database is not sufficient for accurate interpolation; (2) doing the calculations for positrons at energies from $1 \mathrm{keV}$ to $1 \mathrm{MeV}$; and (3) calculating the cross section at higher energies, from $1 \mathrm{MeV}$ to $1 \mathrm{GeV}$, using a much more economical WKB method.

The EPSTAR computer code and database for the calculation, on a personal computer, of electron and positron stopping powers (collision, radiative, and total), CSDA ranges, density-effect corrections, and bremsstrahlung yields, at energies from $1 \mathrm{keV}$ to $10 \mathrm{GeV}$ and for any material, was completed and given to SRD for dissemination.

The cross sections for bremsstrahlung production by electrons with kinetic energies between $1 \mathrm{keV}$ and $10 \mathrm{GeV}$ and differential in emitted photon energy were converted into a computer-readable ASCII data file. The PC software to extract desixed cross sections for any material and energy is in preparation.

The critical review of fluorescence yields and other cross-section data provides sources for the input necessary in the calculation of the energy-absorption coefficients. Numerical evaluation and combination of the pertinent data and distributions for the calculation ingredients include the shell-by-shell photoelectric cross sections and the corresponding fluorescence yields; the incoherent-scattering cross section and the resultant Compton electron energy spectrum; the pair and triplet production cross sections and the resultant energy spectra of electrons and positrons; the bremsstrahlung yield for electrons and positrons slowing down; and the in-flight annihilation of positrons). The development of the necessary codes for these calculations and the preparation of tables of results for all elements are nearly completed. Work on this effort will continue into FY 1991.

Plans for FY 1991 also include extension of our bibliography of experimental photon attenuation coefficients to include compounds. Such a source of information is necessary for thorough comparisons to test the limits of validity for mixture-rule results.

\section{RADIATION CHEMISTRY DATA CENTER}

\section{Director: Alberta B. Ross}

Radiation Laboratory, University of Notre Dame

Notre Dame, Indiana

The Center compiles, evaluates, and disseminates data on chemical reactions and photophysical processes initiated by the interaction of ionizing and photon radiation with matter. The activities particularly focus on primary excited state processes of organic molecules in condensed phases and processes involving transient radicals in aqueous solution. 
During 1990 two major critical reviews were published in the Journal of Physical and Chemical Reference Data.

- "Rate Constants for Reactions of Peroxyl Radicals in Fluid Solutions," P. Neta, R. E. Huie, and A. B. Ross, JPCRD 19, 413 (1990).

0

"Reduction Potentials of One-Electron Couples Involving Free Radicals in Aqueous Solutions," P. Wardman, JPCRD 18, 1637 (1989).

A critique of methods for determination of the molar absorptivity of transient species in solution and selection of preliminary standards by I. Carmichael, G. L. Hug, and $\mathbf{R}$. Bonneau was accepted for publication in Pure and Applied Chemistry by the IUPAC Photochemistry Commission.

Other work completed in FY 1990 included:

- Compilation and evaluation of data on silver, ruthenium, chromium and thallium transients for the compilation project on rate constants for reactions of transient intermediates from metal ions and metal complexes in aqueous solution.

- Extraction of data on the first excited singlet state of molecular oxygen in fluid solution. These data include rate constants for first-order deactivation of singlet oxygen in solution, second-order physical and chemical quenching by substrates in solution and quantum yields for formation of singlet oxygen by energy transfer from various photosensitizers.

A Sun SPARCstation 1 with internal and external disks and a 19-inch monochrome monitor was acquired. Exploratory studies have been initiated on the storage and manipulation of physico-chemical data with database management software from Unify. A high-resolution laser printer was acquired for preparation of camera-ready copy.

Plans for FY 1991 include completion of the Handbook of Photochemistry, which will contain representative photochemical and photophysical data for a large number of organic molecules and other data relevant to the design of photochemical experiments.

\section{THERMODYNAMIC RESEARCH CENTER}

Director: Kenneth N. Marsh

Texas A\&M University

College Station, Texas

The Center provides critically evaluated data on a wide variety of thermodynamic and thermophysical properties of organic compounds. These include thermodynamic properties of organic materials, condensed-phase properties, transition points and properties, density and vapor pressure of liquids, and ideal gas and real gas properties.

During the past year, the effort for SRD was directed towards the evaluation of the thermodynamic properties of organic nitrogen compounds; 1- and 2-butanamine, 2-methyl1-propanamine, 2-methyl-2-propanamine, pyrrole, pyridine, and various substituted pyrroles and pyridines. Earlier work includes the study of eight primary amines. 
Properties being evaluated include condensed-phase properties, perfect gas properties, and thermochemistry. The condensed-phase properties are primarily solid and liquid heat capacities and property changes at phase transitions. The perfect gas properties are thermal functions and the thermochemistry involves enthalpies of formation (from combustion data) and equilibrium constants. Similar work is being completed for organic oxygen compounds. During 1990, a paper has appeared in JPCRD entitled: "Thermodynammic and Thermophysical Properties of Organic Nitrogen Compounds. Part I. Methanamine, Ethanamine, 1- and 2-Propanamine, Benzenamine, 2-, 3-, and 4-Methylbenzenamine".

Concurrent with this work, the data center has an ongoing program for abstracting information on the properties of organic compounds. During the past year, this information has been added to the TRC Source database.

\section{TRIBOLOGY INFORMATION DATA CENTER}

Director: Said Jahanmir

Institute for Materials Science and Engineering, NIST

A computerized tribology information system (ACTIS) is being developed to facilitate technology transfer to industry, to promote cross-disciplinary communication, and to enhance the state-of-the art research.

The Tribomaterials I database built by NIST has been released to ACTIS, Inc. This PC database contains over 200 records of mechanical, physical, and tribological properties for important materials for tribology applications. All the data have been evaluated.

During the past year, work has progressed on building an integrated system of a numerical database and design programs. The work is being done by Intertechnology, Ltd. (UK). The software will be marketed by ACTIS, Inc. Finally, work on a new database for ceramic tribomaterials has been started by NIST experts.

ACTIS work is sponsored by several government agencies and professional societies including NIST, DOE, NSF, and DOD as well as ASLE and ASME and the ACTIS, Inc. Coordination of the activities and supervision of the work is done by the Tribology Group of the Ceramics Division at NIST. 
For the data projects, a summary of the FY 1990 activity is given, as is their source of funding. The data center and data project activities are discussed in more detail in the NIST Technical Activities Reports of the respective divisions in which the center/project organizationally resides.

\section{AMORPHOUS METALS: A JOINT COMPILATION AND EVALUATION PROJECT WITH FACHINFORMATIONSZENTRUY KARISRUHE}

Fachinformationszentrum (FIZ) Karlsruhe

Eggenstein-Leopoldshafen, Germany

Source of Support: NIST

A compilation and evaluation of data on the preparation and properties of amorphous metals is being completed by experts in Germany. This project is jointly supported by NIST and FIZ Karlsruhe. Properties include mechanical, thermophysical and thermodynamic, electrical, magnetic, corrosion, and low-temperature.

\section{CRITICAL COMPILATION OF FATIGUE CRACK PROPAGATION DATA}

\section{S. Tipton}

University of Tulsa

Tulsa, Oklahoma

Source of Support: NSF

Data on the propagation of fatigue cracks in metals is being compiled and evaluated. Emphasis is placed on ascertaining whether or not the data followed ASTM guidleines for their generation and reporting. Raw "a versus N" data are being collected and analyzed using a variety of techniques. The final report will be published in the ASTM Journal of Testing and Evaluation.

\section{BINARY PHASE DIAGRAM EVALUATION - Iron Alloys}

K. Okamoto

ASM International

Metals Park, Ohio

Source of Support: NSF

This evaluation project, now completed, is a major part of the National Institute of Standards and Technology (NIST)-ASM International (ASM) joint program to provide reliable phase stability information to the U.S. materials community. The format of all projects is the same. For each binary system, a recommended phase diagram will be produced with explanatory text including evaluation of available experimental, crystallographic, and thermodynamic data. The outputs will be published first in the Bulletin of Alloy Phase Diagrams and, as larger numbers of systems are completed, in a series of monographs published by ASM. 
K. Money

LaQue Center for Corrosion Technology

Wrightsville Beach, North Carolina

Source of Support: NSF

Stainless steels are widely used in marine construction as materials for heat exchangers, condensers, piping, and other applications. For service below $50{ }^{\circ} \mathrm{C}$, material selection in these environments is generally based on its relative resistance to crevice corrosion. At present, data exist from service experience and laboratory tests.

This extensive database was critically analyzed and summarized. A critical compilation of conditions under which a given material can be expected to undergo crevice corrosion and the rate of that corrosion was published in the ASTM Journal of Testing and Evaluation in 1990. A wide range of stainless steels and service conditions was covered.

\section{CRYSTALLOGRAPHIC DATA FOR ORGANIC MATERIAIS}

0. Kennard

Cambridge Crystallographic Data Centre

Cambridge, England

Source of Support: NIST

The Cambridge Crystallographic Data Centre has had a continuing collaboration with the NIST Crystal Data Center. The Cambridge Centre supplies numerical crystallographic data and references for organic and organometallic materials. From these entries, selected information will be used to update the NIST Crystal Data ID File, which is available for online use.

\section{X-RAY PHOTOELECTRON SPECTROSCOPY DATA BASE PROJECT}

Charles Wagner

Surfax Company

Oakland, California

Source of Support: NSF

Electron Spectroscopy for Chemical Analysis (ESCA) is a technique that has proved of wide importance in characterizing the surface composition of materials. The present project has created a database of critically evaluated line energy for ESCA that was released for distribution in November 1989. Over 10,000 data records have been evaluated. 


\section{POLYMER-POLYMER MISCIBILITY DATA}

S. Krause

Rensselaer Polytechnic Institute

Troy, New York

Source of Support: NSF

Polymer-polymer miscibility data are important in polymer processing. The result of this project will be a complete evaluation of miscibility data. The first part will cover compatible polymers; the second part, immiscible mixtures.

\section{PROPERTIES OF GLASSY-FORMING MELTS}

L. D. Pye

Alfred University

Alfred, New York

Source of Support: NSF

As part of a cooperative data program of the International Commission on Glass, the project is critically examining physical and thermodynamic properties of glassy-forming melts. The resulting compilation will replace existing out-of-date work and will enable the development of further high-tech uses of glass in extreme and unusual service conditions.

\section{SURFACE SPUTTERING YIELD PROJECT}

Joseph Fine

Center for Atomic, Molecular, and Optical Physics, NIST

Sources of Support: DOE and NIST

Sputtering techniques for depth profile are used with a number of methods to analyze compositional changes of materials at surfaces and interfaces. Many of these techniques have matured to being able to provide quantitative sputter depth profile information, yet the necessary data are not readily available in easy-to-use, evaluated form. This project is preparing a compilation of evaluated sputtering yield data for several ion species and energies for targets of pure elements.

CRITICAL COMPILATION OF SURFACE STRUCTURES: COMPARISON OF SEXAFS WITH LEED

P. R. Watson

Oregon State University

Corvallis, Oregon

Source of Support: NSF

Data on surface structures using surface extended $\mathrm{X}$-ray absorption fine structure (SEXAFS) spectroscopy are being evaluated and compared to surface structure data from low energy electron diffraction measurements. The resulting reference data article will finish the complete survey of surface structure measurements. 
T. Gustafsson

Rutgers University

Piscataway, New Jersey

Source of Support: NSF

This project, which is being published by the Journal of Physical and Chemical Reference Data, has provided a critical compilation of data on the absolute coverage of adsorbed molecules or well-characterized transition metal surfaces.

\section{THERMOCHEMICAL DATABASE FOR THE ELEMENTS}

C. B. Alcock

Department of Materials Science and Engineering

University of Notre Dame

Notre Dame, Indiana

Source of Support: NIST

The purpose of the project is to review and evaluate the experimental thermochemical data for the Group IIA elements (beryllium, magnesium, calcium, strontium, barium, and radium) and to develop a PC computerized database which will contain the literature references, evaluated data, recommended values, and curve-fitting routines. The prime deliverable of the work is a set of recommended thermochemical values for the designated Group IIA elements and the background (bibliographic and evaluational) information used in the derivation of the recommended values which will be submitted as a paper for $\mathrm{J}$. Phys. \& Chem. Ref. Data. The paper and PC database are limited to the condensed phase only.

Similar work has begun for the Group IA elements (1ithium, sodium, potassium, rubidium, cesium, and francium).

\section{DATA ON AQUEOUS ELECTROLYTES}

R. Wood

University of Delaware

Newark, Delaware

Source of Support: NSF

This project is closely coordinated with the work of the Aqueous Electrolyte Data Center. It is concerned with the evaluation, correlation, and prediction of data on the thermodynamic properties of aqueous electrolyte solutions. Methods for the computerized transfer of data files are also being investigated.

\section{DIPPR DATA PROJECTS}

\section{AIChE}

New York, New York

Sources of Support: NIST, Industry

DIPPR supports a number of data compilation, evaluation, and prediction projects with cooperative funding from industry and Government. In accordance with an agreement 
between NIST and AIChE, the parent organization of DIPPR, DIPPR and NIST will cooperate in a variety of ways in the production of critically evaluated data for industry.

Currently, NIST is involved directly with several DIPPR activities: the critical evaluation of physical property data of pure compounds, examination of estimation methods for predicting physical property data for organic compounds, and the evaluation of data on the thermodynamic properties of aqueous solutions over a range of temperatures. Two papers are in review which compare and examine test results from the DIPPR Data Prediction Program and a counterpart developed in the Peoples' Republic of China called the Knowledge-Base Organic Physical Property Data System (KB-OPDS).

\section{CRITICAL TABLES OF OBSERVED PROPERTIES OF LIQUID HELIUM, "He}

R. J. Donnelly

University of Oregon

Eugene, Oregon

Source of Support: NSF

Accurate formulations for the observed properties of liquid helium at the saturated vapor pressure have been received in the form of a final report entitled, "The Observed Properties of Liquid Helium: A Critical Compilation." This report also constituted the M.S. Thesis of Robert A. Riegelmann in the Department of Physics at the University of Oregon, December 1990. A publication is planned for JPCRD.

Quantities studied included: the velocities of first, second, third, and fourth sound, entropy, specific heat, thermal conductivity, positive and negative ion mobilities, mutual friction coefficients $B$ and $B^{\prime}$, the dispersion relationship, the vapor pressure scale T58, and the condensate fraction.

\section{CRITICAL EVALUATION AND COMPILATION OF THERMODYNAMIC AND VAPORIZATION DATA FOR METAL SULFIDES}

Paul W. Gilles

Department of Chemistry

University of Kansas

Lawrence, Kansas

Source of Support: NSF

The purpose of the project is to prepare a critical compilation of the thermodynamic and vaporization properties of sulfides of lithium, sodium, potassium, rubidium, and cesium for the gas, liquid, and solid phases. The data to be evaluated will include: calorimetric measurements from low temperatures to room temperature, hightemperature $(700.2500 \mathrm{~K})$ vaporization measurements, solid-state EMF measurements, solubility measurements, high temperature equilibrium measurements in systems containing flowing reactive gases, Knudsen cell mass spectrometric measurements of gas phase systems, and other related spectroscopic measurements. Thermodynamic and vaporization data are of importance to the metallurgical industries, in processes which require corrosion control, recovery of chemicals destined for waste disposal, operation of electrochemical systems, and in the monitoring and regulation of sulfur compounds in pollution control. 


\section{CRITICAL EVALUATION OF HIGH-TEMPERATURE KINETIC DATA}

N. Cohen

Aerospace Corporation

Los Angeles, California

Source of Support: NSF

The aim of this project is the critical evaluation of high-temperature chemical kinetic data in three areas of combustion- and propulsion-related chemistry: (1) the reactions of $\mathrm{H}$ atoms with alkanes; (2) the reactions of $0, \mathrm{H}$, and $\mathrm{OH}$ with ammonia, hydrazine, and other $\mathrm{N}(\mathrm{x}) \mathrm{H}(\mathrm{y})$ species; and (3) high-temperature nitrogen-oxygen chemistry, including neutral, ionized, and electronically excited species. The output of this activity is a series of data sheets, in a format previously developed and utilized, that will be submitted for publication to JPCRD.

\section{CRITICAL STABILITY CONSTANTS AND RELATED THERMODYNAMIC CONSTANTS OF METAL COMPLEXES}

Dr. Arthur E. Martell

Department of Chemistry

Texas A\&M University

College Station, Texas

Source of Support: NIST

A database is in preparation consisting of critical stability constants of metal complexes in aqueous solution and related critical equilibrium constants such as hydrolysis and protonation constants of the complexes, and protonation constants of the complexing agents. In addition to the standard Gibbs energy values, provided in the form of equilibrium constants, the corresponding standard enthalpy values will be evaluated, when available. Stability constants and other thermodynamic constants for aqueous solutions at all temperatures and all ionic strengths of supporting electrolytes will be part of the database. Similarly, solubility product constants $\left(K_{s p}\right)$ for solidsolution equilibria of metal hydroxides and other frequently encountered metal precipitates will be evaluated and included in the database.

NEW METHODS FOR THE DETERMINATION OF AN EQUATION OF STATE FOR MIXTURES OF NITROGEN, ARGON AND OXYGEN, AND OF AIR

R. T. Jacobsen

University of Idaho

Moscow, Idaho

Source of Support: NSF

The objective of this research project is to develop new equations of state for binary and ternary mixtures of the $\mathrm{N}_{2}-\mathrm{Ar}-\mathrm{O}_{2}$ system that are accurate for any mixture composition. The resulting property formulations and property tables will be used in commercial applications including aerospace flight and separation and liquefaction of air. The relatively large quantity of available experimental data for the $\mathrm{N}_{2}-\mathrm{Ar}-\mathrm{O}_{2}$ system provides a unique situation for the study of methods of correlating mixture data.

This project is closely coordinated with work on air at NIST Boulder, and the techniques of the project are being considered for possible use in studies of liquefied natural gas and other hydrocarbon mixtures. 


\section{THERMODYNAMIC PROPERTIES OF ALKENES}

Dr. William V. Steele

National Institute for Petroleum and Energy Research

IIT Research Institute

Bartlesville, Oklahoma

Source of Support: NSF

The purpose of the work is to upgrade the state of thermodynamic data on alkenes so that this functional class of organic compounds will be as well-defined as the alkanes. The objectives of the project are to: collect and assess the available thermodynamic and thermophysical data for $\mathrm{C}_{3}$ alkenes and alkenes with greater carbon numbers, prepare a comprehensive report on the available data assessing reliability, precision, and accuracy, determine and identify gaps in the data where a particular thermodynamic measurement is missing, and derive a comprehensive set of groupadditivity parameters to permit estimation of the thermodynamic properties for alkene where experimental data are poor or unavailable. As part of this effort, a paper has appeared in J. Chem. Thermodynam. during 1990 entitled: "Heat Capacities of Pent-1. ene $(10-320 \mathrm{~K})$, cis-Hex-2-ene $(10-330 \mathrm{~K})$, Non-1-ene $(10-400 \mathrm{~K})$, and Hexadec-1-ene (10$400 \mathrm{~K})^{\prime \prime}$. A final report on the work of the project will result in a publication for JPCRD.

DETERMINATION OF ANCILIARY FUNCTIONS FOR THE REPRESENTATION OF THE VAPOR-LIQUID COEXISTENCE CURVES OF SEVERAL REFRIGERANTS

S. G. Penoncello

Center for Applied Thermodynamic Studies

University of North Dakota

Grand Forks, North Dakota

Source of Support: NSF

The project objective is to develop reference equations for the vapor pressure, saturated liquid density, and saturated vapor density for the following alternative refrigerants $R-22, R-123, R-134 a, R-141 b$, and $R-152 a$ because they do not contribute to the ozone depletion of our atmosphere. New methods of coexistence property prediction were developed where experimental data are unavailable. One fluid and multi-fluid corresponding states models were investigated. Particular attention was given to saturated vapor density values. The accuracy of the resulting equations was confirmed by comparing the calculated properties with the experimental and predicted values. A final report was received October 1990.

This work was coordinated by SRD with similar and related projects at NIST Gaithersburg, NIST Boulder, and the University of Idaho:

\section{PROPERTIES OF POLAR FLUIDS}

Richard F. Kayser

Center for Chemical Technology, NIST

Source of Support: NIST

Major activities in this area include modeling of high-temperature aqueous solutions, determination of the solubility of gases and Henry's constants, reformulation of the refractive index of water and steam, examination of the molecular dynamics of 
hydrogen bonding, investigation of the hydrogen bonding in aqueous solutions, compilation of water and steam data, development of a computer package on refrigerant properties, and participation in IAPS activities.

The NIST Standard Reference Database 23, NIST Thermodynamic Properties of Refrigerants and Refigerant Mixtures (REFPROP) Database, is being up-dated and version 2.0 should be available during FY 1991. In addition, three paper are scheduled for submission to JPCRD during FY 1991 on the summary of international data input on the therrmodynamic properties of water and steam, solubility of $\mathrm{CO}_{2}$ in water, and the refined corresponding states surface for $\mathrm{CO}_{2}+\mathrm{H}_{2} \mathrm{O}$, respectively.

\section{CHEMICAL THERMODYNAMIC PROPERTIES OF POLYCYCLIC AROMATIC HYDROCARBONS}

R. Alberty

Massachusetts Institute of Technology

Cambridge, Massachusetts

Source of Support: NSF

Tables of standard chemical thermodynamic properties of polycyclic aromatic hydrocarbons are being calculated. These tables for the ideal gas phase cover $298 \mathrm{~K}$ to $3000 \mathrm{~K}$ because of the importance of these data in understanding soot formation in flames, the high-temperature vaporization of graphite, and astrophysical calculations. As the number of 6 -member rings increases, the number of different structures with the same number of carbon atoms increases, and the numbers of isomers increase. Therefore, isomer group thermodynamic properties and distributions within isomer groups are being calculated. There is an infinite number of "homologous" series of polycyclic aromatic hydrocarbons, but studying the first half dozen series and the first members for a larger number of series should make it possible to generalize the thermodynamic properties of all polycyclic aromatic isomer groups. Recent work has been completed on the linear regression of pyrene series and the naphthopyrene series of polycyclic aromatic hydrocarbons. A hydrocarbon isomer group database and interactive program are being examined by SRD for future development.

\section{DETERMINATION OF EQUATIONS OF STATE FOR REFRIGERANTS AND REFRIGERANT MIXTURES}

R. T. Jacobsen

Center for Applied Thermodynamic Studies

University of Idaho

Moscow, Idaho

Source of Support: NSF

The project objective is-to develop new reference equations of state for several halocarbon refrigerants which do not contribute to atmospheric ozone depletion. The alternative refrigerants are R-22, R-123, R-134a, R-141b, and R-152a. The use of these fluids in future commercial applications depends on the existence of accurate equations of state. Recent data reported on compressibilities, heat capacities, and velocities of sound have been added to the database used in the development of the new equations of state for these refrigerants. Predicted property values based on extended corresponding states methods were used where experimental data are not available.

This work was coordinated by SRD with similar and related projects at NIST Gaithersburg, NIST Boulder, and the University of North Dakota. 


\section{THERMOPHYSICAL PROPERTIES DATA FOR FLUIDS}

J. V. Sengers

University of Maryland

College Park, Maryland

Source of Support: NSF

This project is concerned with the development of scientifically based and validated representative equations for the thermodynamic and transport properties of fluids as a function of pressure and temperature. The equations are applied to evaluate and synthesize available experimental and theoretical information for the thermophysical properties of fluids in a form suitable for inclusion in data banks.

Recent work has provided an assessment of the thermodynamic properties of sulfur hexafluoride in the critical region.

\section{APPLICATION OF EXPERT SYSTEMS TO CRITICAL EVALUATION OF THERMOPHYSICAL PROPERTY DATA}

J. C. Holste and K. R. Hall

Texas A\&M Research Foundation

College Station, Texas

Source of Support: NSF

This activity involves the design and development of an expert system to assist compilers of thermodynamic data in critical aspects of the evaluation and selection process. The expert system will be interfaced with a large computerized database of numerical experimental values of thermodynamic properties maintained by the Thermodynamics Research Center. An expert system is a computer program that draws on the organized expertise of one or more human experts. Their advice is coded as rules which, along with a knowledge base, constitute the expert system building program. By taking actions specified by the rules, the computer simulates the behavior expected of human experts when solving the same critical data evaluation problem. The system itself also provides a precise record of the process leading to particular selections. By relieving compilers of much of the tedious and routine aspects of their work, it will be possible to carry out frequent and timely analyses of the current state of thermodynamic knowledge in particular areas with greater efficiency and at reduced cost. The process of developing and testing the expert system will also lead to a better formulation and definition of the evaluation and selection procedures. The system itself will serve as a precise record of the processes leading to particular selections.

\section{INTERNATIONAL CENTER FOR THE SYSTEMATIC CORRELATION AND DISSEMINATION OF THE TRANSPORT PROPERTIES OF FLUIDS}

J. Kestin

Brown University

Providence, Rhode Island

Source of Support: NIST

This project supports the Center for the Systematic Correlation and Dissemination of the Transport Properties of Fluids. The Center was established to coordinate the work of the groups associated with the Subcommittee on Transport Properties of Commission I.2 (Thermodynamics) of the International Union of Pure and Applied Chemistry (IUPAC). 
The Subcommittee concerns itself with topics of international scientific or technical significance requiring agreement, regulation, standardization, or codification in some aspect of pure or applied chemistry. There are 10 international cooperating centers for this work: France (1), FRG (3), Japan (1), Norway (1), UK (2), USA (2).

\section{ESTABLISHING CONSISTENT THERMODYNAMIC DATA ON VAPORIZATION EQUILIBRIA IN ONE COMPONENT} SYSTEM

Vladimir Majer

Department of Chemistry and Biochemistry

University of Delaware

Newark, Delaware

Source of Support: NSF

Vapor pressure data are abundant and accurate near the normal boiling point while they are scarce and unreliable in the low-pressure range. Data on thermal properties (enthalpy of vaporization and difference in the heat capacities of an ideal gas and the liquid) are available, however, at temperatures far below the normal boiling point. All three properties are related by exact thermodynamic relationships and can be correlated simultaneously. This procedure can be used in the evaluation of thermodynamic data on vaporization equilibria as a rigorous consistency test and for producing recommended data sets. When a suitable correlation equation is selected, a single set of parameters permits generation of consistent data for several properties between the triple and normal boiling points. The procedure is especially useful for calculating vapor pressures and/or enthalpies of vaporization far below the normal boiling point. The application of this method for establishing the reference data for the selected groups of compounds (alkanols and n-alkanes) is proposed. A universal correlation program will also be produced that will serve as part of the software of a data bank containing thermodynamic properties. In combination with the group contribution methods for estimation of thermal properties, the principle of simultaneous correlation can serve as a base in the formulation of a new approach to the estimation of vapor pressures of high boiling compounds.

\section{COMPUTER PROGRAM ON THERMOPHYSICAL PROPERTIES OF FLUIDS}

William A. Wakeham

IUPAC Thermodynamic Tables Project Centre

Imperial College of Science, Technology, and Medicine

London, England

Source of Support: NSF

The project objective is to provide an interactive program and computerized databases containing complete equations of state and transport properties for pure fluids. The programs and databases are founded upon IUPAC publications prepared at the IUPAC Thermodynamic Tables Project Centre. Recent volumes published deal with thermodynamic tables of the fluid state for oxygen (volume 9), ethylene (volume 10), and fluorine (volume 11). Volumes on sulfur hexafluoride (volume 12) and methanol (volume 13) are in preparation. 


\section{VIBRATIONAL AND ELECTRONIC ENERGY LEVELS OF SMALI POLYATOMIC TRANSIENT MOLECULES}

Marilyn E. Jacox

Center for Atomic, Molecular and Optical Physics, NIST

Source of Support: NIST

The purpose of this project is to compile and evaluate vibrational and electronic energy levels of small polyatomic transient molecules.

Two major outputs were completed during FY 1990:

0

NIST Vibrational and Electronic Energy Levels of Small Polyatomic Transient Molecules Database, Standard Reference Database 26 (VEEL) released in June, 1990, contains vibrational and electronic energy level data for 1024 transient molecules with from 3 to 16 atoms.

0

"Vibrational and Electronic Energy Levels of Polyatomic Transient Molecules. Supplement I," scheduled to appear in the November-December 1990 issue of Journal of Physical and Chemical Reference Data, represents a major extension of the earlier publications on these two topics and contains data for approximately 500 transient molecules.

Plans for FY 1991 include support and extension of the database and production of an update to the PC Database (VEEL).

To avoid the confusion inherent in using several supplements, the next updated hardcopy version of the evaluated vibrational and electronic energy leve database will be complete, with projected publication in 1993 as a monograph. 
AAAS

AAPM

ACerS

ACS

AIAA

AIChE

AIME

AIP

API

APL

APS

ASM

ASME

ASTM

BAPD

CAC

CAD

CAM

CAMOP

CAS

CCE

CCT

CINDAS

CIS

CISTI

CODATA

CRR

CSIN

DARCOM

DARPA

DECHEMA

DIPPR

DOD

DOE

EMF

EPA

ESCA

EXAFS

FDA

FIZ

FY

GPE

GPSDC

GRI

HP

IAPWS

ICDD

ICSU
American Association for the Advancement of Science

American Association of Physicists in Medicine (AIP)

American Ceramic Society

American Chemical Society

American Institute of Aeronautics and Astronautics

American Institute of Chemical Engineers

American Institute of Mining, Metallurgical, and Petroleum Engineers

American Institute of Physics

American Petroleum Institute

Johns Hopkins Applied Physics Laboratory

American Physical Society

American Society for Metals International

American Society of Mechanical Engineers

American Society for Testing and Materials

Bulletin of Alloy Phase Diagrams

Center for Analytical Chemistry, NML, NIST

Computer-Aided Design

Computer-Aided Manufacturing

Center for Atomic, Molecular, and Optical Physics

Chemical Abstracts Service

Center for Chemical Engineering, NEL, NIST

Center for Chemical Technology, NML, NIST

Center for Information and Numerical Data Analysis and

Synthesis, Purdue University

Chemical Information System

Canada Institute for Scientific and Technical Information

Committee on Data for Science and Technology (ICSU)

Center for Radiation Research, NML, NIST

Chemical Substances Information Network

Department of The Army Command

Defense Advanced Research Projects Agency

Deutsche Gesellschaft fur chemisches Apparatewesen

Design Institute for Physical Property Data (AIChE)

U. S. Department of Defense

U. S. Department of Energy

Electro-Motive Force

U. S. Environmental Protection Agency

Electron Spectroscopy for Chemical Analysis

Extended X-ray Absorption Fine Structure

Food and Drug Administration

Fachinformationszentrum

Fiscal Year

General Purpose Equipment

General Purpose Scientific Document Code

Gas Research Institute

Hewlett-Packard

International Association for the Properties of Water and Steam

International Centre for Diffraction Data (JCPDS)

International Council of Scientific Unions 
IMSE

INCRA

IUPAC

JANAF

JANNAF

JCAMP

JCPDS

JCPDS - ICDD

JILA

LEED

MPC

MPD

MSDC

NACE

NAS

NAVLAP

NIST

NCI

NEL

NIH

NLM

NML

NMR

NRC

NSF

NSRDS

NTIS

$\mathrm{OA}$

OMS

ONR

OSTP

PDFC

PL

PMFC

PMS

RCDC

SAE

SPE

SRD

SRM

STN

STRS

UNESCO

USGS
Institute for Materials Science and Engineering

International Copper Research Association

International Union of Pure and Applied Chemistry (ICSU)

Joint Army, Navy, Air Force (historical acronym)

Joint Army, Navy, NASA, Air Force

Joint Committee on Atomic and Molecular Physical Data

Joint Committee on Powder Diffraction Standards

JCPDS-International Centre for Diffraction Data

Joint Institute for Laboratory Astrophysics, NML,

NIST-University of Colorado

Low Energy Electron Diffraction

Materials Properties Council

Material Property Data Network

Mass Spectral Data Centre (UK)

National Association of Corrosion Engineers

National Academy of Sciences

National Voluntary Laboratory Accreditation Program

National Institute of Standards and Technology

National Cancer Institute

National Engineering Laboratory, NIST

National Institutes of Health

National Library of Medicine

National Measurement Laboratory, NIST

Nuclear Magnetic Resonance

National Research Council

National Science Foundation

National Standard Reference Data System

National Technical Information Service

Other Agency (Funding)

Office of Measurement Services, NML, NIST

Office of Naval Research

Office of Science and Technology Policy

Phase Diagrams for Ceramists Data Center

Public law

Precision Measurements - Fundamental Constants

Physical Measurement Services

Radiation Chemistry Data Center

Society of Automotive Engineers

Society of Plastics Engineers

Standard Reference Data

Standard Reference Materials

Scientific and Technical Information Network

Scientific and Technical Research and Services

(appropriated NIST funds)

United Nations Educational, Scientific, and Cultural

Organization

United States Geological Survey 
STANDARD REFERENCE DATA

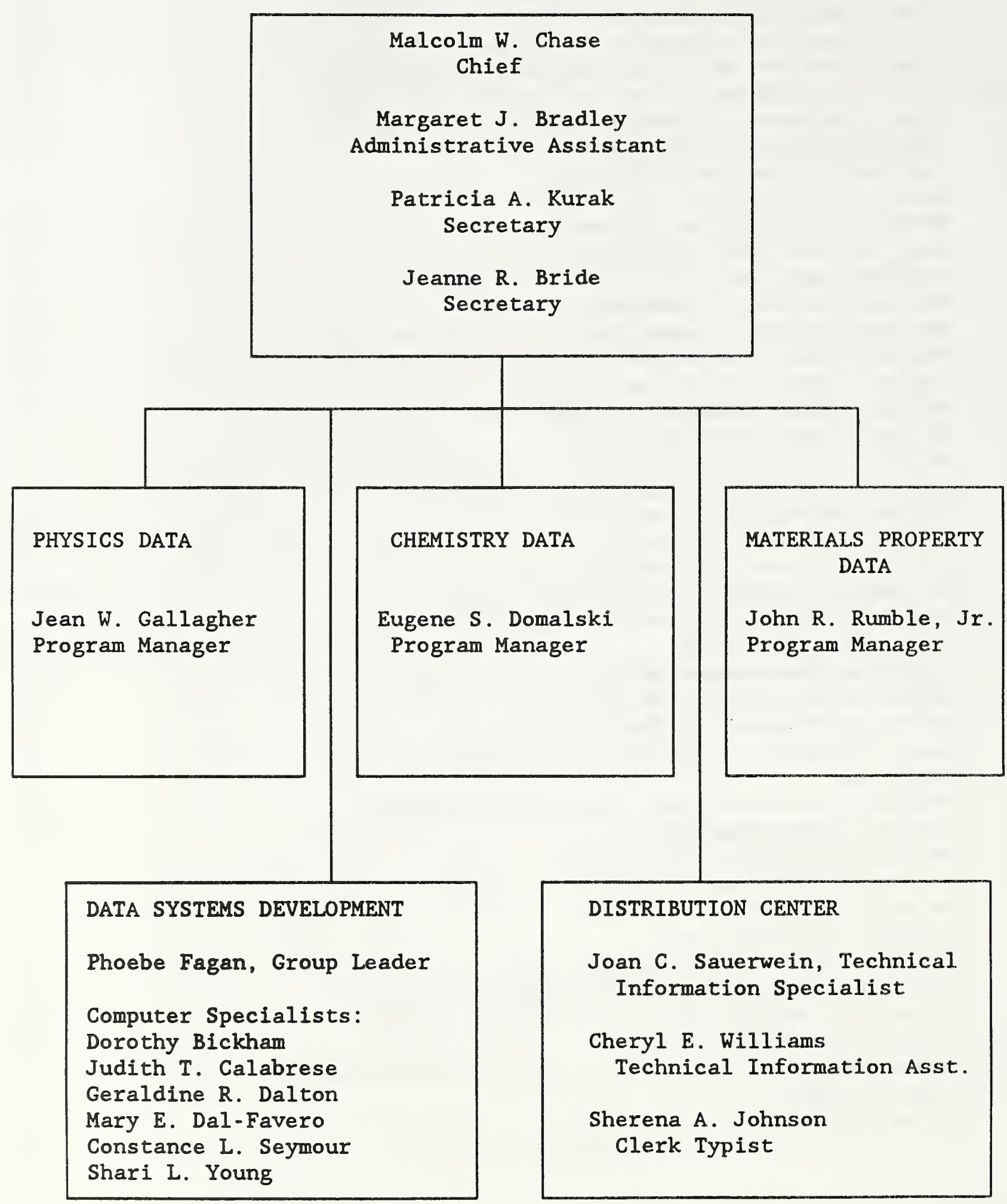

December 1990 
Chief - Dr. Malcolm W. Chase

Secretary, Mrs. Patricia A. Kurak

Secretary, Mrs. Jeanne R. Bride

Telephone: (301) 975-2200

Administrative Assistant - Mrs. Margaret J. Bradley

Telephone: (301) 975-2202

Fiscal and budgetary matters; contracting; procurement; personnel.

Program Manager - Dr. Jean W. Gallagher

Telephone: (301) 975-2204

Management of Physics Data Program - atomic, molecular, and nuclear properties data.

Program Manager - Dr. Eugene S. Domalski

Telephone: (301) 975-2205

Management of Chemistry Data Program - kinetic, thermochemical, and thermophysical data.

Program Manager - Dr. John R. Rumble, Jr.

Telephone: (301) 975-2203

Management of Materials Property Data Program - mechanical properties, corrosion, phase diagrams.

Distribution Center - Mrs. Joan C. Sauerwein

Assistant, Ms. Cheryl Williams

Clerk Typist, Ms. Sherena Johnson

Telephone: (301) 975-2208

Distribution of databases; coordination of SRD publication process; response to data inquiries from the public; maintenance of NSRDS collection of main NIST Library and SRD Reference Center holdings.

Guest Scientist - Dr. Lewis H. Gevantman

Telephone: (301) 975-2210

As Secretary of IUPAC Commission on Solubility Data, plans and monitors progress of work of the Commission and looks for opportunities for joint data activities with NSRDS data centers. 
Guest Scientist - Dr. David R. Lide

Telephone: (301) 975-2201

Editor, Journal of Physical and Chemical Reference Data, As President of CODATA and Chairman of the IUPAC Committee on Chemical Databases, oversees the work of these two international groups, including cooperative projects in which NIST scientists participate.

Guest Scientist - Dr. Howard J. White, Jr.

Telephone: (301) 975-3190

Monitors the activities of DIPPR, the International Association for the Properties of Steam, and related organizations in the preparation of numerical databases and consults on such activities of importance to NIST or involving NIST participation.

Data Systems Development Group - Mrs. Phoebe Fagan

Telephone: (301) 975-2213

Oversight of SRD activities related to automation, database development and dissemination; System manager and consultant for SRD Computer Facilities.

Mrs. Dorothy Bickham

Telephone: (301) 975-2524

Software development and application for data automation and dissemination; database design and implementation.

Mrs. Judith T. Calabrese

Telephone: (301) 975-2215

Oversight of the Bedford Composition system including system management and consulting; programming for system control, data conversion, and computer typesetting; coordination of user interfaces to the composition system.

Mrs. Geraldine R. Dalton

Telephone: (301) 975-2214

Development of software for data automation; design of database systems; automation of data center activities; preparation of databases for distribution.

Mrs. Constance L. Seymour

Telephone: (301) 975-2217

Publication control of NSRDS manuscripts for computer typesetting; processing and pagination of files received from outside data centers through composition system. 
Mrs. Mary E. Dal-Favero

Telephone: (301) 975-2219

Programming for data automation and dissemination; processing of files for typesetting; preparation of graphics for publications.

Miss Shari L. Young

Telephone: (301) 975-2212

Development and utilization of software for data automation and dissemination; major assistance in SRD Computer Facilities support. 
"The Biological Macromolecule Crystallization Database: A Tool for Developing Crystallization Strategies," Gilliland, Gary L. and Bickham. Dorothy M., Methods: A Companion to Methods in Enzymology, Vol. 1, No. 1, August, pp. 6-11, (1990).

"NIST Standard Reference Data Products 1990 Catalog," Malcolm W. Chase (editor) SP782, May 1990.

"Heat Capacities and Entropies of Organic Compounds in the Condensed Phase." Domalski, E.S., Hearing, E.D., Volume II., J. Phys. \& Chem. Ref. Data, 19, 8811047 (1990).

"NIST Estimation of the Thermodynamic Properties for Organic Compounds at 298.15 K. Part I. Hydrocarbon Compounds", Domalski, E.S., Hearing, E.D., NIST Technical Note 1274, User's Guide, 45pp. and Diskette, June 1990 (NIST Standard Reference Database 18).

"Thermochemistry of High-Energy Reactions", Domalski. E.S., and Jobe, T.J., Jr., Proceedings of the 1989 U.S. Army Chemical Research, Development, and Engineering Center Scientific Conference on Chemical Defense Research, November 1417, 1989, Aberdeen Proving Ground, D (CRDEC-SP-024, prepared by J.D. Williams, $\mathrm{Jr}$. ) pages 339-345, August 1990.

"Assessing the Credibility of the Calorific Content of Municipal Solid Waste", Domalski.E.S., Churney, K.L., Ledford, A.E.,Jr., Colbert, J.C., Bruce, S.S., Buckley, Paule, R.C., and Reilly, M.L., Pure and Appl. Chem. to appear in the December 1990 issue as part of the Proceedings of the 11th IUPAC Conference on Chemical Thermodynamics held in Como, Italy, August 26-31, 1990.

Multiphoton Bibliography 1987-1988, NBS-LP-92 Supp. 6, S.J. Smith, J.H. Eberly, and J.W. Gallagher, editors, June 1990.

Nonequilibrium Effects in Ion and Electron Transport-Jean W. Gallagher, David F. Hudson, Erich E. Kunhardt, and Richard J. Van Brunt (editors), Plenum Press, NY, $464 \mathrm{p}$.

Report to the International Astronomical Union Commission 14, Atomic and Molecular Data. Part 3. Collisional Cross Sections-J.W. Gallagher, Transactions of the International Astronomical Union (1990).

"Thermodynamic Properties of the Alkaline Earth Hydroxides, A JANAF Case History," Malcolm W. Chase, Materials Chemistry at High Temperatures, Vol. 1, pp 207-214, John W. Hastie, editor, Humana Press, Clifton, NJ, 1990.

"Database Systems in Science and Engineering," J, R, Rumble, Jr, and F. J. Smith (Adam Hilger, London, 1990). 
Malcolm W. Chase

"Thermodynamic Properties of Gas Phase Species of Importance to Ozone Depletion," 11th IUPAC Conference on Chemical Thermodynamics, Como, Italy, August 26-31, 1990.

"Thermodynamic Properties of Elemental Boron," 10th International Symposium on Boron, Borides and Related Compounds. Albuquerque, NM, August 27-30, 1990.

\section{Eugene S. Domalski}

"Historical Survey of the MSW/RDF Characterization Program at NBS/NIST from 1970 to 1990" ASME Research Committee on Industrial and Municipal Wastes, Washington, DC, March 13, 1990.

"Twenty Years of Characterization of MSW/RDF at NIST and Opportunities for the Future," Solid Waste Management Workshop, sponsored by Midwest Universities Consortium, Inc., Lake Bluff, IL, May 1, 1990.

"Mechanisms to Enhance Funding for Thermodynamic Research," 45th Annual Calorimetry Conference, University of Michigan, Ann Arbor, MI, July 23-27, 1990.

"Assessing the Credibility of the Calorific Content of Municipal Solid Waste," 11th IUPAC Conference on Chemical Thermodynamics, Como, Italy, August 26-31, 1990; (talk on Aug. 28, 1990).

"Thermodynamic Responses to Environmental Problems at the Molecular Level," 11th IUPAC Conference on Chemical Thermodynamics, Como, Italy, August 26-31, 1990; (talk on Aug. 28, 1990).

"A Thermodynamic Approach to the Risk Assessment of Chemicals at the Molecular Level," 11th IUPAC Conference on Chemical Thermodynamics, Como, Italy, August 26-31, 1990; (talk on Aug. 28, 1990).

\section{Phoebe Fagan}

"Database Development in the Standard Reference Data Program," Scientific Computing and Automation Conference, Philadelphia, PA, September 18-20, 1990.

\section{Jean W. Gallagher}

"Databases of Atomic Collisions Cross Sections," Federation of Analytical Chemistry and Spectroscopy Societies (FACSS), Chicago, IL, October 1989.

"Program Manager's Perspective of IRM in DoC," DOC Information Resources Management Conference, Annapolis, MD, (October 1989).

"The Standard Reference Data Program at NIST," NSF Physics Program - Informal meeting (December 1989). 
"The Standard Reference Data Program at NIST," NIST Div. of Analytical Chemistry Lunch Bunch (March 1990).

"SRD/NIST Interest in Developing New Databases for Analytical Chemistry," Spectral Database Advisory Committee Meeting (March 1990), New York, NY.

"The Standard Reference Data Program at NIST," Scientific Computing and Automation, Philadelpia, PA, September 18, 1990.

\section{John R. Rumble}

"Overview of Standardization Dynamics of Materials Databases" 14th Annual Conference on Composites Materials, Cocoa Beach, FL, January 17, 1990.

"Materials Databases," Alternatives in Glass Research Symposium, Gaithersburg, MD, March 23, 1990

"Overview of Materials Database Standards Activity," ASTM Organizational Meeting on Chemical Databases, Boston, MA, April 27, 1990.

"The NIST X-ray Photoelectron Spectroscopy Database," Eastern Electron Spectroscopy Symposium, Wilmington, DE, May 17, 1990.

"Databank and Terminology Requirements for the Development of a Classification System for Ceramics", Ispra Italy, June 21, 1990.

"ASTM Committee E49 Activities," ASTM E49 European Meeting, Gothenburg, Sweden, June $30,1990$.

"Database Standards and Data Models - A Materials View and More," 11th International CODATA Conference, Columbus, OH, July 17, 1990.

"Materials Database Standards, " Database Task Force, American Concrete Institute, Gaithersburg, MD, September 12, 1990.

"ASTM Committee E49 Activities," Executive Committee of ASTM Committee A1 on Steel, Naperville, IL, September 26, 1990.

"Materials Databases," DuPont, Wilmington, DE, September 28, 1990.

"Computerization of MIL-Handbook 5, the NIST Experience," MIL-HDBK-5 Committee, Cocoa Beach, FL, October 16, 1990.

"The NIST Materials Data Program-Into the 1990s," NIST, November 19, 1990. 
Biophysical Society Annual Meeting - Baltimore, Maryland, February 19, 1990

Pittsburgh Conference - New York, New York - March 5-9, 1990

CODATA Conference - Columbus, Ohio - July 15-19, 1990

EnvironACS (American Chemical Society) - Washington, DC - July 17-19, 1990

American Chemical Society National Exposition - Washington, DC - August 27-29, 1990

ASM Materials Applications \& Services Expositione - Detroit, Michigan - October $9-11,1990$

Society of Environmental Toxicology and Chemistry (SETAC) 90 - Arlington, Virginia - November 11-15, 1990

Federal Librarians Information \& Communications Conference (FLICC) - National Institutes of Health, Bethesda, Maryland - November 26-27, 1990 


\section{Dorothy M. Bickham}

Baltimore-Washington, DC, Hewlett Packard UNIX Users Group

Mid-Atlantic Oracle Users' Group

INTEREX HP Users' Conference, Boston

Judith T. Calabrese

Bedford Composition System Users Group

TypeX, GraphX, and ArtX trade shows

GraphExpo Trade Show

Malcolm W. Chase

CODATA Task Group on Chemical Thermodynamic Tables (Chairman)

Engineering Sciences Data Unit Ltd., Physical Data and Reaction Kinetics Committee (Corresponding Member)

ASTM E27 Hazard Potential of Chemicals (Chairman)

ASTM E49 Computerization of Material Property Data (E49.53 Subcommittee Chairman)

Journal of Physical and Chemical Reference Data (Editorial \& Management Board)

ACS Task Force on Numerical Scientific Data

Geraldine R. Dalton

Mid-Atlantic Oracle Users' Group

Baltimore-Washington, DC, Hewlett Packard UNIX Users' Group

Mary E. Dal-Favero

Baltimore-Washington, DC, Hewlett Packard UNIX Users' Group

Hewlett Packard Users Group

Eugene S. Domalski

American Society of Mechanical Engineers - Research on Industrial and Municipal Wastes

ASTM E27 Hazard Potential of Chemicals

ASTM E38 Resource Recovery 
IUPAC Subcommittee on Thermodynamic Data of the Commission I.2 on Thermodynamics (Secretary)

Design Institute for Physical Properties Data (DIPPR) (AIChE)

\section{Phoebe Fagan}

User Committee for Scientific Computing, NIST

Baltimore-Washington, DC, Hewlett Packard UNIX Users' Group (Chairman)

\section{Jean Gallagher}

AIP Committee on Numerical Databases

Joint Committee on Atomic and Molecular Physics

NRC Committee on Line Spectra

IAU Commission 非14

David R. Lide, Jr.

American Institute of Physics (AIP Publication Board)

Committee on Nomenclature, ACS

Journal of Physical and Chemical Reference Data (Editor)

Committee on Data for Science and Technology of International Council of Scientific Unions (President)

Committee on Chemical Databases, IUPAC (Chairman)

Advisory Council, Engineering Information, Inc.

Advisory Committee, Particle Data Center, Lawrence Berkeley Laboratory

International Council for Scientific and Technical Information (Executive Committee)

ACS Task Force on Numerical Scientific Data (Chairman)

Editorial Board, Journal of Chemical Information and Computer Science

U. S. Advisory Committee for the International Council of Scientific Unions John Rumble

ASTM Committee E-49 on Computerization of Material Property Data (Chairman) ISO/TC184/SC4/WG3 Standard for the Exchange of Product Model Data, Materials Project (Chairman) 
ASTM Committee on Publications

ASTM Committee E-42 Surface Analysis

National Materials Property Data Network - Technical Advisory Group

NBS/International Centre for Diffraction Cooperative Program on Crystal Data Management Board

NIST-ACTIS, Inc., Management Board on Tribology Data

VAMAS Technical Working Area 10 on Materials Databanks (Chairman)

ASM International - Metals Information Committee

Alloy Phase Diagram International Commission - NIST Representative

Constance L. Seymour

Bedford System Users' Assoc.

SEBA 3-yr Board Member

Typex, Graphx, Artx Trade Show

GraphExpo Trade Show

Howard J. White

International Association for Properties of Steam (Executive Secretary)

ASME Research and Technology Committee on Water and Steam in Thermal Power Systems (Member)

Design Institute for Physical Properties Data (DIPPR) (AIChE) (Member)

Administrative Committee

Technical Committee (non-voting)

Liaison Committee

Data Compilation Project Advisory Committee

Electrolyte Data Project Advisory Committee

Journal of Chemical and Engineering Data (Editorial Advisory Board)

Shari L. Young

Baltimore-Washington, DC, Hewlett Packard UNIX Users' Group

INTEREX HP Users' Conference, Boston 


\author{
Public Law 90-396 \\ 90 th Congress, H. R. 6279 \\ July 11,1968
}

\title{
An Act
}

To proride for the collection, compilation. critical evaluation, publication, and sale of standard reterence data.

Be it enacted by the Senate and Honse of Representatives of the Cinited s'tates of -t merica in C'ongress assembled,

Standard Refor ence Data Aot.

DECLARATION OF POLICY

Secrios 1. The Congress hereby finds and declares that reliable standardized scientific and technical reference dara are of vital im. portance to the progrress of the Nation s science and technology. It is therefore the policy of the Congress to make criticully evaluated reference dara readily available to scientists, engineers, and the general public. It is the purpose of this tct to strengthen and enhamce this policy.

DEFIXITIONS

82 STAT. 339

82 STAT. 340

SEC. 2. For the purposes of this det-

(a) The rerm "stindard reference data" means quantitative inforination. related to at measurable physical or chemical property of it substance or system of substances of known composition and structure. which is critically evaluated as to its reliability under section of this Act.

(b) The term "Secretury" means the Secretary of Commerce.

SEC. \%. The Secretary is athorized and directed to provide or ar- Colleotlon and range for the collection, compilation. critical evaluation. publication. publiostion of and dissemination of standard reference data. In carrying out this standard refer procram. the Secretary shall, to the maximum extent practicable. nulize the reference data services and facilities of other ingencies and instrumentalities of the Federal fovernment and of Stare and local governm ${ }^{\infty}$ is. persons, tirms. institutions. and associations, with their consent $a \mathrm{i}$ : and factitita. il it encies and instrumentalities of the Federal Gov. emmen sioe t: ged to exercise their duties and functions in such manner ts wil is. sist in carrying out the purpose of this -1ct. This section shall ie decmed complementary to existing authority, and norhing herein is intended to repent. supersede, or diminish existing authority or responsibility of any agency or instrumentality of the Federnl (iovernment.

SEC. 4 . To provide for more effectire integration and coordination of standard reference data activities, the secretary, in consultation with other interested Federal aurencies, shall prescrilie and publish in the Federal Register sucis standards. criteria. and procedures for the prepantion and publication of standard reference data as may be necessary to earry out the provisions of this Ict.

SEc. כ. Standard reference data conforming to standards established by the Secretary may be made alvailable and sold by the Secretary or by a person or arency designated by him. To the extent practicable and appropriate, the prices established for such data inay reflect the cost of collection, compilation, evaluarion, pnblication. and dissemination of the data. including alminist rative expenses: and the amounts received shall be subject to the .Let of Mitrch $: i, 1901$, als amended (1i)

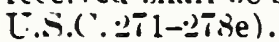

SEc: 6. (a) Notwithstanding the limitations contaned in section

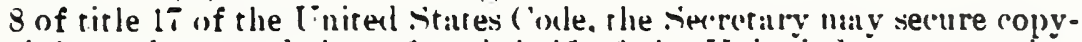
right and renewal therest on belaulf of the l"niteil states as anthor or proprietor in all or any paut of any stalidard reference data which

Standards, eto. Publiontion in Foderel Reglster.

Sele of rofer ence data. Cost reovery. 


\section{Pub. Law 90-396
STAT. 340 \\ $-2-$ \\ July 11,1968}

he prepires or makes arailable under this Act, and may authorize the reproduction and publication thereof by others.

(b) The publication or republication by the Government under this Act. either separately or in a public document, of any material in which copyright is subsisting shall not be taken to cause any abridgment or innulment of the copyright or to authorize any use or appropriation of such material without the consent of the copyright proprietor.

Appropriation.

SEC. 7 . There are atuthorized to be appropriated to carry out this Act. $\$ 1.86$ million for the tiscal yeur ending June 30, 1969. Notwithstanding the provisions of any other law, no appropriations for any fiscal year may be made for the purpose of this Act after fiscal year 1969 unless previously authorized by legislation hereafter enacted by the ('ongress.

Short titie.

SFc. 8 . This Act may be cited as the "Standard Reference Data Act." Approved July 11, 1968.

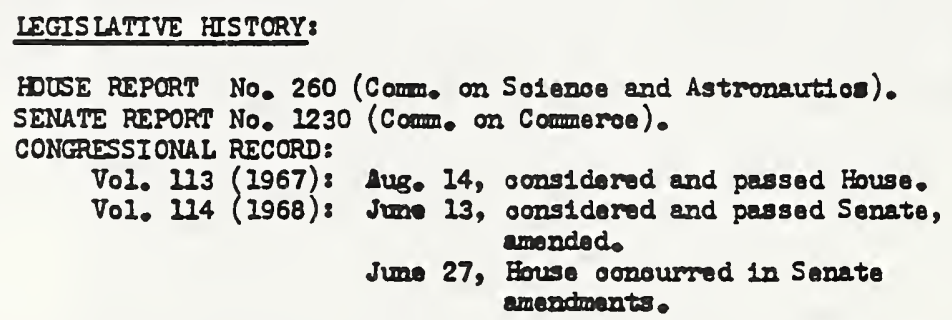


STANDARD REFERENCE DATA PROGRAM: Manages the National Standard Reference Data System (NSRDS) which provides critically evaluated data on physical and chemical properties of materials to scientists, engineers, and the general public; assesses the need for reliable data in industry, government, and universities; coordinates NIST data activities with those of other Government agencies, private organizations, and international bodies; establishes and supports data centers which compile and evaluate data from the world scientific literature; stimulates research needed to fill important gaps in the available data; and disseminates recommended data through a variety of publication and reference services tailored to user needs.

DATA SYSTEMS DEVELOPMENT GROUP (231.01): Develops and programs user interfaces for commercially-destined PC databases; standardizes and optimizes user interface and search efficiency for databases developed by NSRDS data activities; works with data centers to identify computersoftware and equipment requirements and recommends appropriate solutions; designs and implements database management systems and interfaces for internal data center use; typesets articles for publication in the Journal of Physical and Chemical Reference Data; and maintains two UNIX computers and a variety of microcomputers in support of the above activities. 
Alloy Phase Diagram Data Center

Dr. Neville Pugh

Materials B1dg. - Room B261

National Institute of Standards and Technology

Gaithersburg, MD 20899

Telephone: (301) 975-6040

Aqueous Electrolyte Data Center

Dr. David Neumann

Chemistry Bldg. - Room Al64

National Institute of Standards and Technology

Gaithersburg, MD 20899

Telephone: (301) 975-2525

Atomic Collision Cross Section Data Center

Dr. John Broad

Joint Institute for Laboratory Astrophysics

University of Colorado

Boulder, CO 80309-0440

Telephone: (303) 492-7801

Bitnet - KROG @ JILA

Atomic Energy Levels Data Center

Dr. William C. Martin

Physics Bldg. - Room Al65

National Institute of Standards and Technology

Gaithersburg, MD 20899

Telephone: (301) 975-3212

Atomic Transition Probabilities Data Center

Dr. Wolfgang L. Wiese

Physics Bldg. - Room A265

National Institute of Standards and Technology

Gaithersburg, MD 20899

Telephone: (301) 975-3200

Chemical Kinetics Data Center

Dr. John T. Herron

Chemistry Bldg. - Room Al47

National Institute of Standards and Technology

Gaithersburg, MD 20899

Telephone: (301) 975-2569 
Chemical Thermodynamics Data Center

Dr. Eugene S. Domalski

Chemistry Bldg. - Room A155

National Institute of Standards and Technology

Gaithersburg, MD 20899

Telephone: (301) 975-2526

Corrosion Data Center

Dr. David Anderson

Materials Bldg. - Room B254

National Institute of Standards and Technology

Gaithersburg, MD 20899

Telephone: (301) 975-6026

Crystal Data Center

Dr. Alan D. Mighell

Materials Bldg. - Room A207

National Institute of Standards and Technology

Gaithersburg, MD 20899

Telephone: (301) 975-6254

Fluid Mixtures Data Center

Dr. James F. Ely

National Institute of Standards and Technology Boulder, CO 80303

Telephone: (303) 497-5467

FTS $320-5467$

Fundamental Constants Data Center

Dr. Barry N. Taylor

Metrology Bldg. - Room B258

National Institute of Standards and Technology Gaithersburg, MD 20899

Telephone: (301) 975-4220

Ion Kinetics and Energetics Data Center

Dr. Sharon Lias

Chemistry Bldg. - Rocm A147

National Institute of Standards and Technology

Gaithersburg, MD 20899

Telephone: (301) 975-2562 
Molecular Spectra Data Center

Dr. F. J. Lovas

Physics Bldg. - Room B268

National Institute of Standards and Technology

Gaithersburg, MD 20899

Telephone: (301) 975-2385

Molten Salts Data Center

Dr. George J. Janz

Rensselaer Polytechnic Institute

Department of Chemistry

Troy, NY 12181

Telephone: (518) 276-6344

*National Center for Thermodynamic Data on Minerals

Dr. Bruce S. Hemingway

U.S. Geological Survey

U.S. Department of the Interior

959 National Center

Reston, VA 22092

Telephone: (703) 648-6755

NIST Mass Spectrometry Data Center

Dr. Sharon Lias \& Dr. Stephen E. Stein

Chemistry Bldg. - Room A261

National Institute of Standards and Technology

Gaithersburg, MD 20899

Telephone: (301) 975-2562 or $975-2505$

Phase Diagrams for Ceramists Data Center

Dr. Stephen Freiman

Materials Bldg. - Room A229

National Institute of Standards and Technology

Gaithersburg, MD 20899

Telephone: (301) 975-5761

Photon and Charged-Particle Data Center

Dr. Stephen Seltzer

Radiation Physics Bldg. - Room C311

National Institute of Standards and Technology

Gaithersburg, MD 20899

Telephone: (301) 975-5551 
Radiation Chemistry Data Center

Dr. Alberta B. Ross

University of Notre Dame

Radiation Laboratory

Notre Dame, IN 46556

Telephone: (219) 239-6527

FTS $333-8220$

Structural Ceramics Data Center

Dr. Ron Munro

Materials Bldg. - Room A256

National Institute of Standards and Technology

Gaithersburg, MD 20899

Telephone: (301) 975-6127

Thermodynamics Research Center

Dr. Kenneth N. Marsh

Thermodynamics Research Center

Texas A\&M University

College Station, TX 77843-3111

Telephone: (409) 845-4971

Tribology Information Activity

Dr. Said Jahanmir

Metrology Building, Room A215

National Institute of Standards and Technology

Gaithersburg, MD 20899

Telephone: (301) 975-3671

* Standard Reference Data is not involved at the present time in the administration or funding of this data center but assists in making their outputs and services known to the scientific community. There is also considerable interaction between this data center and the Chemical Thermodynamics Data Center. 


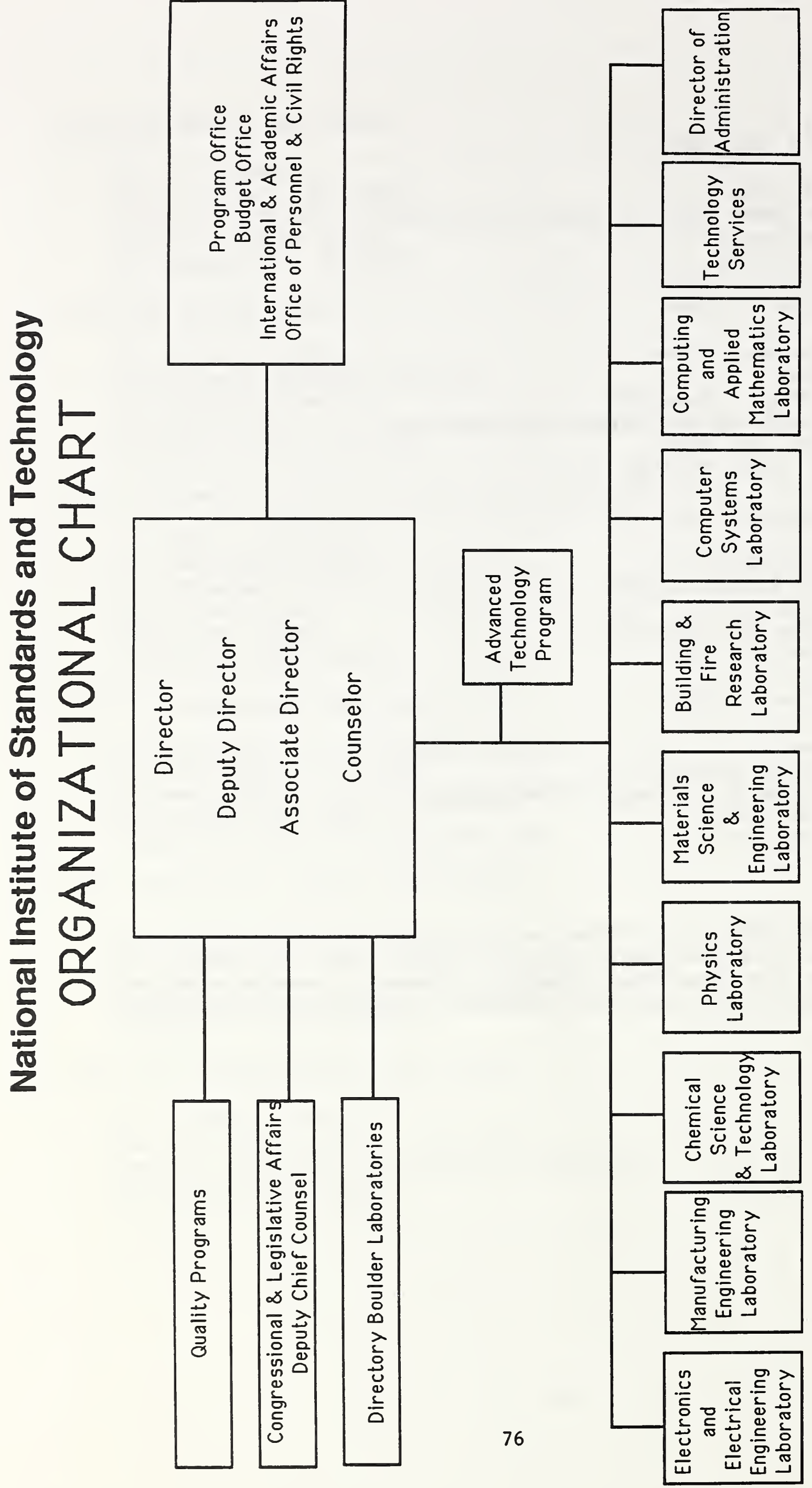

APPENDIX $\mathrm{K}$ 


\section{TECHNOLOGY SERVICES}

MANUFACTURING TECHNOLOGY CENTERS PROGRAM

\section{INFORMATION SERVICES}

OFFICE OF STANDARDS SERVICES

Standards Code and Information Program Standards Management Program

Weights and Measures Program
OFFICE OF TECHNOLOGY COMMERCIALIZATION

Research and Technology Applications Program

Technology Development and Small Business Program

State Technology Extension Program
OFFICE OF MEASUREMENT SERVICES

Standard Reference Data Program

Standard Reference Materials Program

Physical Measurement Services Program Laboratory Accreditation Program

\section{OFFICE OF INVENTIONS} EVALUATION

Energy-Related Inventions Program

Non-Energy-Related Inventions Program 



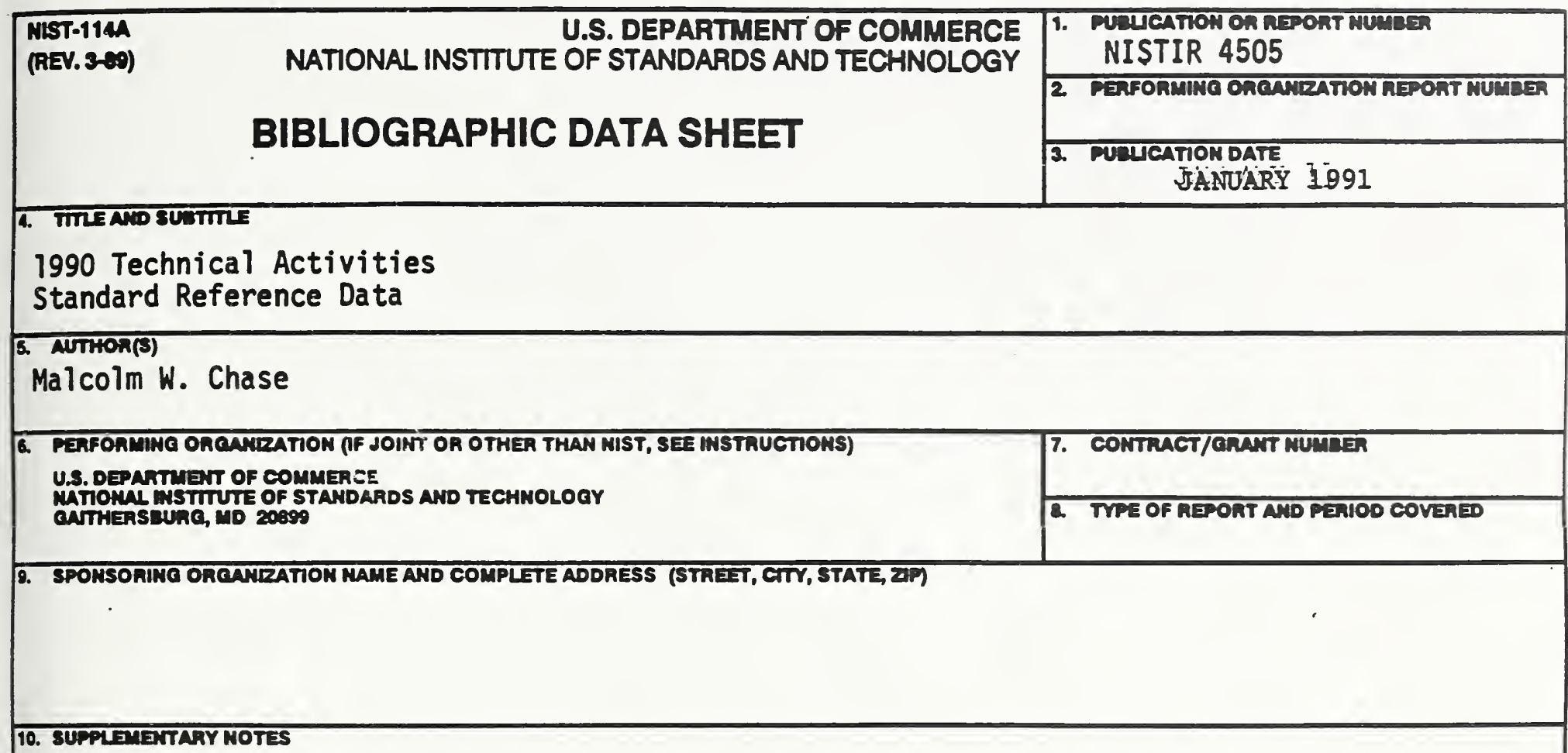

10. SUPPLIETTARY NOTES

DOCUMETT DESCRIBES A COMPUTER PROGRAM; SF-185, FPS SOFTWARE SULMATY, IS ATTACHED.

11. ABSTRACT (A 2O0-WOAD OR LESS FACTUAL SUMMARY OF MOST SICMIFCANT MFORMATIOH. FF DOCUMETT WCUDES A SIONIFICANT EIBUOCRAPHY OR UTERATURE SUTVEY, MENTION IT HERE)

Standard Reference Data is a program office within the Office of Measurement Services in Technology Services, National Institute of Standards and Technology. Standard Reference Data develops and disseminates publications and databases of critically evaluated physical, chemical and materies properties of substances. These publications and databases are available through NIST and private publications, on magnetic tape, PC diskettes, and from on-line.

Standard Reference Data is responsible for management and coordination of the program. Work is carried out through a decentralized network of data centers and projects referred to as the National Standard Reference Data System (NSRDS). This volume summarizes the activities of the program for the year 1990.

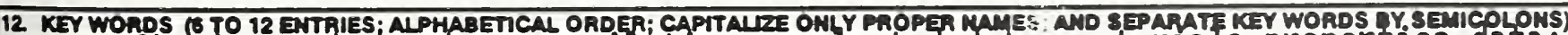
Chemistry data; data compilation; evaluated data; materials properties data; numerical database; physics data; standard reference data; technical activities 1990.

POR OFFCLL DISTRIBUTION. DO MOT REUEASE TO MATHOMAL TECHMCNL MFORMATION SEMVEE (MTIS).

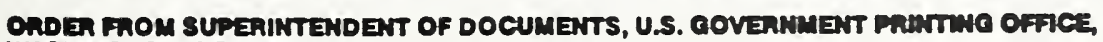
WASHWATOH, DC 20402

ORDER FMOM MATOMAL TECHNICAL INFORMATION SEMMCE (NTS), SPRMGFED, VA 22101.

14. NUMEEA OF PRINTED PAQES

16. PNICE A04 


